Article

\title{
Isomorphic Circuits of Independent Amplitude Tunable Voltage-Mode Bandpass Filters and Quadrature Sinusoidal Oscillators
}

\author{
San-Fu Wang ${ }^{1}$, Hua-Pin Chen ${ }^{2, * \mathbb{D}}$, Yitsen $\mathrm{Ku}^{3}$ and Wei-Yuan Chen ${ }^{2}$ \\ 1 Department of Electronic Engineering, National Chin-Yi University of Technology, Taichung 41170, Taiwan; \\ sf_wang@ncut.edu.tw \\ 2 Department of Electronic Engineering, Ming Chi University of Technology, New Taipei 24301, Taiwan; \\ M09158012@o365.mcut.edu.tw \\ 3 Department of Electrical Engineering, California State University Fullerton, Fullerton, CA 92831, USA; \\ joshuaku@fullerton.edu \\ * Correspondence: hpchen@mail.mcut.edu.tw; Tel.: +886-2-2908-9899; Fax: +886-2-2908-5247
}

check for

updates

Citation: Wang, S.-F.; Chen, H.-P.; $\mathrm{Ku}, \mathrm{Y}$;; Chen, W.-Y. Isomorphic Circuits of Independent Amplitude Tunable Voltage-Mode Bandpass Filters and Quadrature Sinusoidal Oscillators. Appl. Sci. 2021, 11, 7431. https://doi.org/10.3390/app11167431

\section{Academic Editors:}

Wen-Hsiang Hsieh, Jia-Shing Sheu and Minvydas Ragulskis

Received: 26 July 2021

Accepted: 10 August 2021

Published: 12 August 2021

Publisher's Note: MDPI stays neutral with regard to jurisdictional claims in published maps and institutional affiliations.

Copyright: (c) 2021 by the authors. Licensee MDPI, Basel, Switzerland. This article is an open access article distributed under the terms and conditions of the Creative Commons Attribution (CC BY) license (https:// creativecommons.org/licenses/by/ $4.0 /)$.

\begin{abstract}
This paper presents isomorphic circuits of voltage-mode (VM) non-inverting bandpass filters (NBPFs) and VM quadrature sinusoidal oscillators (QSOs) with independent amplitude control functionality. The proposed VM NBPFs and VM QSOs exhibit low-output impedance and independent amplitude control, which are important for easily cascading the VM operation and independent control of the amplitude gain. The proposed isomorphic circuits employ three LT1228 commercial integrated circuits (ICs), two grounded capacitors, two grounded resistors and one floating resistor. The use of grounded capacitors is beneficial for the implementation of the IC. Both NBPFs have a high-input impedance and have a wide range of independent amplitude tunable passband gain without affecting the quality factor $(Q)$ and center frequency $\left(f_{o}\right)$. The $Q$ and $f_{o}$ parameters of the proposed NBPFs are orthogonal tunability. By feeding back each input signal to the output response of the NBPF, two VM fully uncoupled QSOs are also proposed. The proposed VM fully uncoupled QSOs have two quadrature sinusoidal waveforms with two lowoutput impedances and one independent amplitude tunable sinusoidal waveform. The frequency of oscillation (FO) and the condition of oscillation (CO) are fully uncoupled and controlled electronically. The performances of the proposed isomorphic circuits have been tested with a \pm 5 volt power supply and are demonstrated by experimental measurements which confirm the theoretical assumptions.
\end{abstract}

Keywords: analog circuit design; non-inverting bandpass filter; fully uncoupled quadrature oscillator; LT1228

\section{Introduction}

The LT1228 is a commercial integrated circuit (IC) using bipolar or complementary metal oxide semiconductor (CMOS) technology. It combines a transconductance amplifier (OTA) and a current feedback amplifier (CFA). LT1228 is one of the attractive components used for realizing voltage-mode (VM) analog circuits. It has wider electronic tunability, higher accuracy, higher frequency applicability and simplicity of implementation, so many topologies based on LT1228 application circuits have been published in the literature [1-8]. In addition, many active filters and oscillators based on different active components have also been presented in the literature, and they have been widely used in signal generation applications [9-20].

An active VM non-inverting bandpass filter (NBPF) is one of the important filters for analog signal processing, and its transfer function can be expressed as

$$
\frac{\mathrm{V}_{\mathrm{NBPF}}}{\mathrm{V}_{\mathrm{in}}}=\frac{\mathrm{ds}}{\mathrm{as}^{2}+\mathrm{bs}+\mathrm{c}}
$$


where the coefficients $a, b, c$ and $d$ are real numbers, $V_{\text {in }}$ is the NBPF input signal and $V_{\text {NBPF }}$ is the output response. According to the feedback theory, the VM quadrature sinusoidal oscillator (QSO) can be synthesized by connecting the input voltage of the NBPF to the output response. Therefore, Equation (1) can be rewritten as Equation (2):

$$
\left[\mathrm{as}^{2}+(\mathrm{b}-\mathrm{d}) \mathrm{s}+\mathrm{c}\right] \mathrm{V}_{\mathrm{NBPF}}=0
$$

Based on Equations (1) and (2), the VM QSO can be realized by zeroing the input voltage of the NBPF, and the characteristic equation (CE) of the VM QSO can be expressed as Equation (3):

$$
C E: a s^{2}+(b-d) s+c=0
$$

The two poles of Equation (3) are obtained as follows:

$$
s_{1,2}=\frac{-(b-d) \pm \sqrt{(b-d)^{2}-4 a c}}{2 a}=\frac{(d-b)}{2 a} \pm j \sqrt{\frac{c}{a}-\left(\frac{d-b}{2 a}\right)^{2}}
$$

In Equation (3), the oscillator will oscillate if the condition of oscillation (CO) and the frequency of oscillation (FO) are as given by Equations (5) and (6), respectively:

$$
\begin{gathered}
C O: b=d \\
\text { FO }: \omega_{O}^{2}=\frac{c}{a}
\end{gathered}
$$

For a positive feedback system, if the two poles of Equation (4) are located in the right half of the complex plane, the circuit can be built, and the sinusoidal oscillation can be maintained. Therefore, the CO of Equation (5) is modified to become Equation (7):

$$
\mathrm{CO}: \mathrm{b} \leq \mathrm{d}
$$

Recently, two interesting VM circuits were proposed in the literature [21,22]. The circuit proposed in [21] employs five OTAs combined with two grounded capacitors. The circuit proposed in [22] also employs five OTAs combined with two grounded capacitors. However, the passband gain of these two circuits cannot be adjusted independently without affecting the quality factor $(Q)$ and resonance angular frequency $\left(\omega_{\mathrm{o}}\right)$, and it cannot be transformed into an electronically controllable QSO with an independent amplitude control function [21,22]. An interesting VM QSO with gain controllability of the quadrature voltage output was recently proposed in [23]. The circuit in Figure 5 of [23] employs three LT1228s, two grounded capacitors, two grounded resistors and three floating resistors, but the resistances of the circuit in Figure 5 of [23] are not the smallest. According to the feedback theory, this study proposes isomorphic circuits of the VM NBPFs and VM QSOs with independent amplitude control functionality. Each of the isomorphic circuits contains three LT1228 commercial ICs, two grounded capacitors, two grounded resistors and one floating resistor. Table 1 lists the available circuits and compares them according to the relevant standards. The additional performance comparisons with previous circuits are summarized in Tables 2 and 3. As shown in Tables 1-3, the proposed VM NBPFs and VM QSOs exhibit high-input and low-output impedance and independent amplitude control, which are important for easily cascading the VM operation and independent control of the amplitude gain. The range of the measured QSO amplitude can be adjusted from 1.51 to 24.05 , and the measured oscillation frequency can be varied from $82.15 \mathrm{kHz}$ to $1629 \mathrm{kHz}$. This means that the proposed circuits are sufficient for the typical impedance sensor applications [23]. Because the proposed isomorphic circuits have independent amplitude control functions and a wide tunable frequency range, the applications will be beneficial in the literature $[23,24]$. 
Table 1. Comparison between recent electronic tunable filter/oscillator circuits.

\begin{tabular}{|c|c|c|c|c|c|}
\hline Parameter & $\begin{array}{l}\text { Figures } 1 \text { and } \\
2 \text { in }[21]\end{array}$ & $\begin{array}{l}\text { Figures } 1 \text { and } \\
\quad 4 \text { in }[22]\end{array}$ & $\begin{array}{c}\text { Figure } 5 \\
\text { in [23] }\end{array}$ & $\begin{array}{l}\text { First Proposed } \\
\text { in This Work }\end{array}$ & $\begin{array}{l}\text { Second Proposed } \\
\text { in This Work }\end{array}$ \\
\hline Number of active devices & 5 (OTA) & 5 (OTA) & 3 (LT1228) & 3 (LT1228) & 3 (LT1228) \\
\hline Number of passive elements & $2(2 \mathrm{C})$ & $2(2 \mathrm{C})$ & $7(2 \mathrm{C}, 5 \mathrm{R})$ & $5(2 C, 3 R)$ & $5(2 C, 3 R)$ \\
\hline Orthogonal tunability of $\omega_{\mathrm{O}}$ and Q & yes & yes & NA & yes & yes \\
\hline $\begin{array}{l}\text { High-input and low-output } \\
\text { impedance of the filter }\end{array}$ & no & no & NA & yes & yes \\
\hline $\begin{array}{l}\text { Independent tunability of the filter } \\
\text { amplitude }\end{array}$ & no & no & NA & yes & yes \\
\hline $\begin{array}{l}\text { Electronic and linear tune of } \\
\text { oscillation frequency }\end{array}$ & no & yes & yes & yes & yes \\
\hline $\begin{array}{l}\text { Oscillator } \mathrm{CO} \text { and } \mathrm{FO} \text { with fully } \\
\text { uncoupled electronic tuning law }\end{array}$ & no & yes & yes & yes & yes \\
\hline Oscillator's amplitude tunability & no & no & yes & yes & yes \\
\hline
\end{tabular}

Note: Q: quality factor; $\omega_{\mathrm{o}}$ : resonance angular frequency; CO: condition of oscillation; FO: frequency of oscillation; and NA: not available.

Table 2. The additional performance comparisons with previous VM filters.

\begin{tabular}{ccccc}
\hline Parameter & Figure 1 in [21] & Figure 1 in [22] & $\begin{array}{c}\text { First Proposed in } \\
\text { This Work }\end{array}$ & $\begin{array}{c}\text { Second Proposed in } \\
\text { This Work }\end{array}$ \\
\hline $\begin{array}{c}\text { Supply voltage } \\
\text { Measured power dissipation }\end{array}$ & $\pm .14 \mathrm{~W}$ & $\pm 15 \mathrm{~V}$ & $\pm 5 \mathrm{~V}$ & $\pm 5 \mathrm{~V}$ \\
Designed center frequency & $159.16 \mathrm{kHz}$ & $1.2 \mathrm{~W}$ & $0.22 \mathrm{~W}$ & $0.22 \mathrm{~W}$ \\
Measured maximum operating & $0 \mathrm{~dB}$ & $217 \mathrm{kHz}$ & $165.8 \mathrm{kHz}$ & $165.8 \mathrm{kHz}$ \\
voltage gain & -14.6 & $0 \mathrm{~dB}$ & $27.86 \mathrm{~dB}$ & $27.58 \mathrm{~dB}$ \\
$\begin{array}{c}\text { Measured output P1dB (dBm) } \\
\text { Measured IMD3 (dBc) }\end{array}$ & -42.86 & $\mathrm{NT}$ & -11.4 & -9.77 \\
Measured third-order intercept & -5.47 & -31.16 & -40.1 & -39.66 \\
point (dBm) & $\mathrm{NT}$ & $\mathrm{NT}$ & -7.95 & -5.753 \\
Measured phase noise (dBc/Hz) & $\mathrm{NT}$ & $\mathrm{NT}$ & -83.86 & -73.87 \\
Figure of merit & $\mathrm{NT}$ & $3.07 \times 10^{6}$ & $3.08 \times 10^{6}$ \\
\hline
\end{tabular}

Note: P1dB: 1-dB compression point; IMD3: third-order intermodulation distortion; and NT: not tested.

Table 3. The additional performance comparisons with previous VM oscillators.

\begin{tabular}{|c|c|c|c|c|c|}
\hline Parameter & $\begin{array}{c}\text { Figure } 2 \\
\text { in [21] }\end{array}$ & Figure 4 in [22] & $\begin{array}{c}\text { Figure } 5 \\
\text { in }[23]\end{array}$ & $\begin{array}{l}\text { First Proposed } \\
\text { in This Work }\end{array}$ & $\begin{array}{l}\text { Second Proposed } \\
\text { in This Work }\end{array}$ \\
\hline Supply voltage & $\pm 15 \mathrm{~V}$ & $\pm 15 \mathrm{~V}$ & $\pm 5 \mathrm{~V}$ & $\pm 5 \mathrm{~V}$ & $\pm 5 \mathrm{~V}$ \\
\hline Measured power dissipation & NT & $1.2 \mathrm{~W}$ & $1.98 \mathrm{~W}$ & $0.22 \mathrm{~W}$ & $0.22 \mathrm{~W}$ \\
\hline $\begin{array}{c}\text { Measured total harmonic } \\
\text { distortion (\%) }\end{array}$ & NT & NT & $<1.26$ & 0.81 & 0.33 \\
\hline $\begin{array}{l}\text { Measured frequency tunable } \\
\text { range }(\mathrm{kHz})\end{array}$ & NT & $150.1 \sim 2653$ & $8.21 \sim 1117.51$ & $82.15 \sim 1629$ & $80.83 \sim 1626$ \\
\hline $\begin{array}{l}\text { Measured amplitude } \\
\text { tunability range }\end{array}$ & NA & NA & $1.97 \sim 15.92$ & $1.51 \sim 24.05$ & $1.51 \sim 24.03$ \\
\hline Measured phase noise $(\mathrm{dBc} / \mathrm{Hz})$ & NT & -73.23(@1000 Hz) & NT & -40.18 (@ $30 \mathrm{~Hz})$ & -34.7 (@30 Hz) \\
\hline
\end{tabular}

Note: NA: not available; and NT: not tested.

\section{The Proposed Isomorphic Circuits}

Each of the isomorphic circuits' symbols of an LT1228 commercial IC from Linear Technology [25] is shown in Figure 1a, and its packed IC is shown Figure 1b. The LT1228 IC contains an OTA with a specially devised CFA. Figure 1c shows the equivalent circuit of 
the LT1228 IC, and the ideal port relations of LT1228 can be characterized by the following hybrid matrix [23]:

$$
\left[\begin{array}{c}
\mathrm{I}_{\mathrm{V}+} \\
\mathrm{I}_{\mathrm{V}-} \\
\mathrm{I}_{\mathrm{y}} \\
\mathrm{V}_{\mathrm{x}} \\
\mathrm{V}_{\mathrm{w}}
\end{array}\right]=\left[\begin{array}{ccccc}
0 & 0 & 0 & 0 & 0 \\
0 & 0 & 0 & 0 & 0 \\
\mathrm{~g}_{\mathrm{m}} & -\mathrm{g}_{\mathrm{m}} & 0 & 0 & 0 \\
0 & 0 & 1 & 0 & 0 \\
0 & 0 & 0 & \mathrm{R}_{\mathrm{T}} & 0
\end{array}\right]\left[\begin{array}{c}
\mathrm{V}_{+} \\
\mathrm{V}_{-} \\
\mathrm{V}_{\mathrm{y}} \\
\mathrm{I}_{\mathrm{x}} \\
\mathrm{I}_{\mathrm{w}}
\end{array}\right]
$$

where $g_{m}$ is the transconductance gain of the LT1228 IC and $R_{T}$ is the transresistance gain of the CFA. Ideally, $R_{T}$ approaches infinity, and the $g_{m}$ is controlled by the direct current (DC) bias current $\left(I_{B}\right)$ of $L T 1228$. The $g_{m}$ value is equal to 10 times the value of $I_{B}$ and can be expressed as $[23,25]$

$$
\mathrm{g}_{\mathrm{m}}=10 \mathrm{I}_{\mathrm{B}}=\frac{\mathrm{V}_{\mathrm{DD}}-\mathrm{V}_{\mathrm{EE}}-2 \mathrm{~V}_{\mathrm{BE}}}{\mathrm{R}_{\mathrm{B}}}
$$

where $V_{D D}$ is the positive voltage supply and $V_{E E}$ is the negative voltage supply. $V_{\mathrm{BE}}$ is a bias voltage of the bipolar junction transistor and is approximately equal to 0.65 volts. $R_{B}$ is a bias control resistor used to obtain the $\mathrm{DC}$ bias current $\mathrm{I}_{\mathrm{B}}$. The proposed two isomorphic circuits are shown in Figures 2 and 3. Each of the circuits contains three LT1228 commercial ICs, two grounded capacitors, two grounded resistors and one floating resistor. The use of grounded capacitors is beneficial for the implementation of the IC. Each input voltage of the VM NBPF (Figures 2a and 3a) is applied to the positive voltage terminal of the LT1228, so it has a high-input impedance and can be easily cascaded without any voltage buffers. The output impedances of terminals $\mathrm{V}_{\mathrm{BP} 2}$ and $\mathrm{V}_{\mathrm{BP} 5}$ (Figures 2a and 3a, respectively) are very small, so they can also be directly connected to the next stage without any voltage buffers. Moreover, the VM NBPF responses of $\mathrm{V}_{\mathrm{BP} 3}$ and $\mathrm{V}_{\mathrm{BP}}$ shown in Figures 2a and 3a, respectively, can achieve a wide range of independent amplitude adjustable passband gains without affecting the parameters of $f_{o}$ and $Q$.

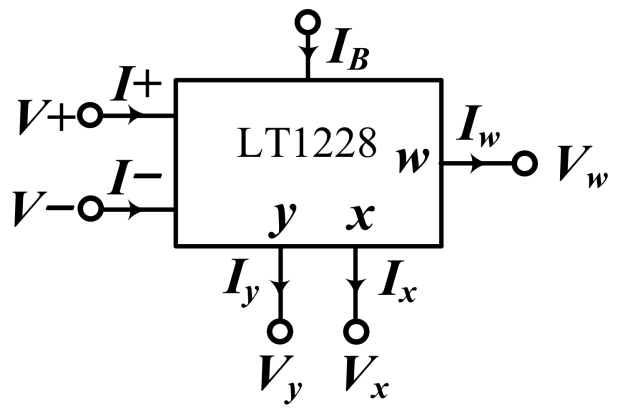

(a)

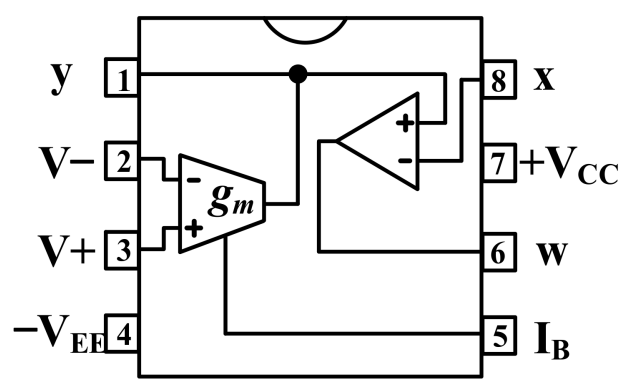

(b)

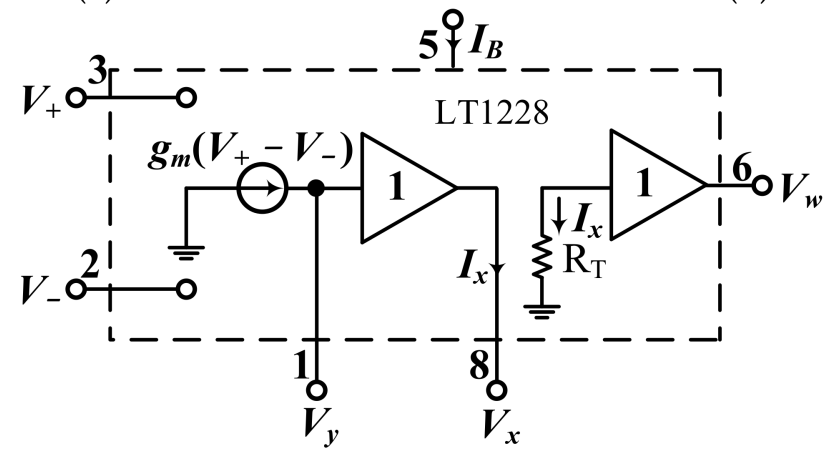

(c)

Figure 1. LT1228. (a) Schematic symbol. (b) Pin. (c) Equivalent circuit. 


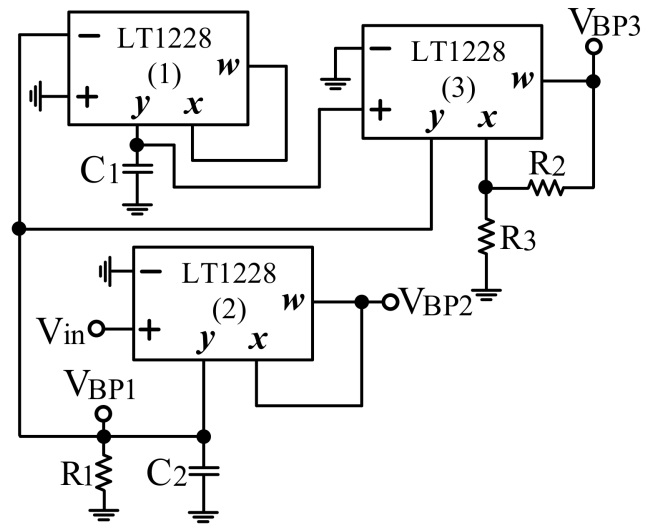

(a)

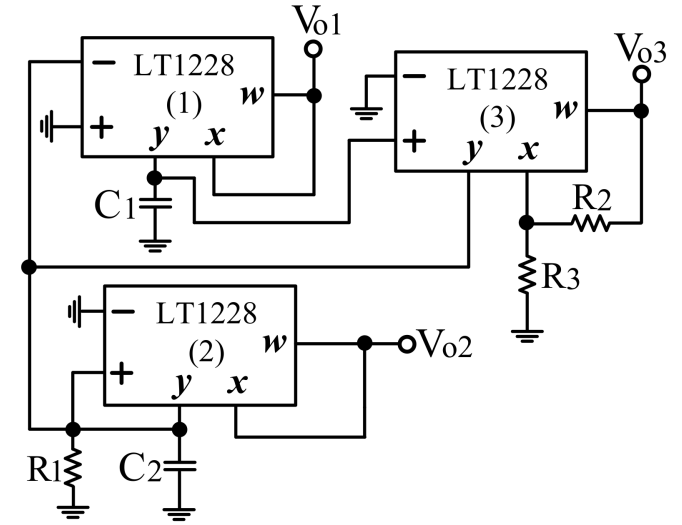

(b)

Figure 2. The first proposed isomorphic circuit of the VM NBPF and VM QSO. (a) VM NBPF circuit. (b) VM QSO circuit.

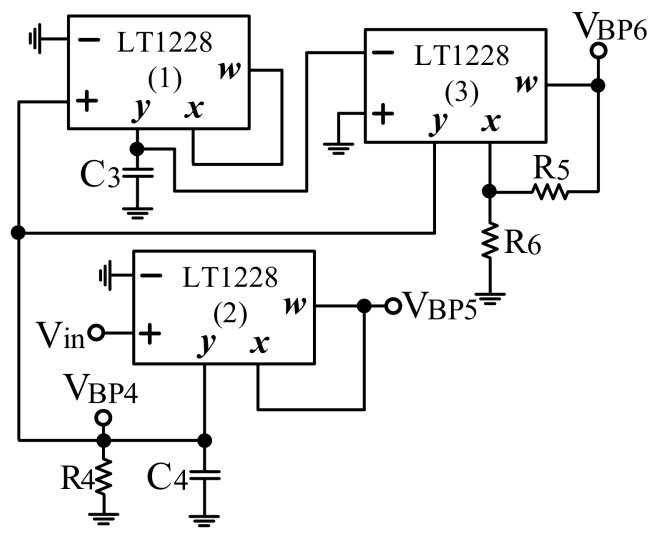

(a)

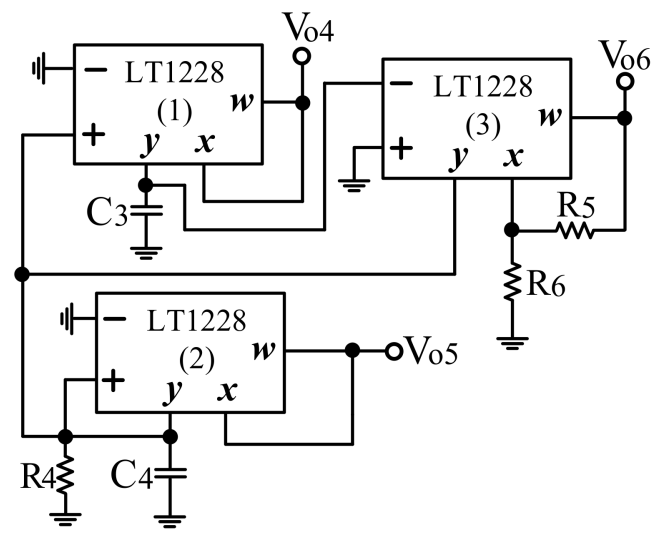

(b)

Figure 3. The second proposed isomorphic circuit of the VM NBPF and VM QSO. (a) VM NBPF circuit. (b) VM QSO circuit.

Routine analysis of the VM NBPF circuit (Figure 2a) yielded the following three NBPF responses:

$$
\begin{gathered}
\frac{V_{\text {BP1 }}}{V_{\text {in }}}=\frac{s C_{1} g_{m 2} R_{1}}{s^{2} C_{1} C_{2} R_{1}+s C_{1}+g_{m 1} g_{m 3} R_{1}} \\
\frac{V_{\text {BP2 }}}{V_{\text {in }}}=\frac{s C_{1} g_{m 2} R_{1}}{s^{2} C_{1} C_{2} R_{1}+s C_{1}+g_{m 1} g_{m 3} R_{1}} \\
\frac{V_{\text {BP3 }}}{V_{\text {in }}}=\left(\frac{s C_{1} g_{m 2} R_{1}}{s^{2} C_{1} C_{2} R_{1}+s C_{1}+g_{m 1} g_{m 3} R_{1}}\right)\left(1+\frac{R_{2}}{R_{3}}\right)
\end{gathered}
$$

Based on the three NBPF responses from Equations (10)-(12), the NBPF parameters of $\mathrm{f}_{\mathrm{o}}$ and $\mathrm{Q}$ are given by

$$
\begin{gathered}
f_{o}=\frac{1}{2 \pi} \sqrt{\frac{g_{m 1} g_{m 3}}{C_{1} C_{2}}} \\
Q=R_{1} \sqrt{\frac{C_{2} g_{m 1} g_{m 3}}{C_{1}}}
\end{gathered}
$$

From Equations (13) and (14), the NBPF parameters of $f_{0}$ and $Q$ have orthogonal tunability by tuning the $g_{m 1}$ for $f_{o}$ first and then the grounded resistor $R_{1}$ for $Q$ without affecting parameter $\mathrm{f}_{\mathrm{o}}$. 
The passband gains of the three NBPF responses are given by

$$
\begin{aligned}
& \mathrm{H}_{\mathrm{BP} 1}=\mathrm{H}_{\mathrm{BP} 2}=\mathrm{g}_{\mathrm{m} 2} \mathrm{R}_{1} \\
& \mathrm{H}_{\mathrm{BP} 3}=\mathrm{g}_{\mathrm{m} 2} \mathrm{R}_{1}\left(1+\frac{\mathrm{R}_{2}}{\mathrm{R}_{3}}\right)
\end{aligned}
$$

From Equations (15) and (16), it is important to note that the passband gains of the NBPF responses are independently adjustable by $g_{\mathrm{m} 2}$ without affecting the NBPF parameters of $f_{o}$ and $Q$. Moreover, the resistors $R_{2}$ or $R_{3}$ in Equation (16) can achieve a wide range for the independent amplitude adjustable passband gain of the NBPF without affecting parameters $f_{o}$ and $Q$. It is interesting to note that, as shown in Figure 2a, by feeding back the input signal to the output response of the NBPF, a VM fully uncoupled QSO can be realized as shown in Figure $2 b$. This means that the input signal $V_{\text {in }}$ is connected to $\mathrm{V}_{\mathrm{BP} 1}$ (Figure 2a), and Equation (10) becomes

$$
\left.\frac{V_{\text {BP } 1}}{V_{\text {in }}}\right|_{V_{B P 1}=V_{\text {in }}}=1=\frac{\mathrm{sC}_{1} g_{m 2} R_{1}}{\mathrm{~s}^{2} C_{1} C_{2} R_{1}+s C_{1}+g_{m 1} g_{m 3} R_{1}}
$$

Therefore, the CE of Figure $2 b$ is expressed as

$$
\mathrm{s}^{2} \mathrm{C}_{1} \mathrm{C}_{2} \mathrm{R}_{1}+\mathrm{sC}_{1}\left(1-\mathrm{g}_{\mathrm{m} 2} \mathrm{R}_{1}\right)+\mathrm{g}_{\mathrm{m} 1} \mathrm{~g}_{\mathrm{m} 3} \mathrm{R}_{1}=0
$$

Based on Equation (18), the CO and FO of the proposed VM QSO (Figure 2b) are given by Equations (19) and (20), respectively:

$$
\begin{gathered}
\text { CO: } g_{m 2} R_{1} \geq 1 \\
\text { FO : } f_{o}=\frac{1}{2 \pi} \sqrt{\frac{g_{m 1} g_{m 3}}{C_{1} C_{2}}}
\end{gathered}
$$

According to Equations (19) and (20), the CO can be fully controlled independently without affecting the $\mathrm{FO}$ by adjusting $\mathrm{g}_{\mathrm{m} 2}$ or $\mathrm{R}_{1}$, and the $\mathrm{FO}$ can be also fully controlled independently without affecting the CO by adjusting $\mathrm{g}_{\mathrm{m} 1}$ or $\mathrm{g}_{\mathrm{m} 3}$. Hence, the VM QSO (Figure $2 \mathrm{~b}$ ) provides a fully uncoupled tuning law for the $\mathrm{CO}$ and $\mathrm{FO}$. Routine analysis of the QSO structure, shown in Figure 2b, yielded the following two quadrature voltage outputs and a sinusoidal output waveform with independent amplitude control:

$$
\begin{gathered}
\frac{V_{\mathrm{o} 1}}{V_{\mathrm{o} 2}}=-\left.\frac{g_{\mathrm{m} 1}}{\mathrm{sC}_{1}}\right|_{\mathrm{s}=\mathrm{j} \omega_{\mathrm{o}}}=\frac{g_{\mathrm{m} 1}}{\omega_{\mathrm{o}} \mathrm{C}_{1}} \mathrm{e}^{\mathrm{j} 90^{\circ}}=\sqrt{\frac{\mathrm{C}_{2} \mathrm{~g}_{\mathrm{m} 1}}{\mathrm{C}_{1} \mathrm{~g}_{\mathrm{m} 3}} \mathrm{e}^{\mathrm{j} 90^{\circ}}} \\
\mathrm{V}_{\mathrm{o} 3}=\left(1+\frac{\mathrm{R}_{2}}{\mathrm{R}_{3}}\right) \mathrm{V}_{\mathrm{o} 2}
\end{gathered}
$$

According to Equation (21), the magnitude ratio and phasor of output voltages $V_{\mathrm{o} 1}$ and $\mathrm{V}_{\mathrm{o} 2}$ are given as

$$
\begin{gathered}
\left|\frac{\mathrm{V}_{\mathrm{o} 1}}{\mathrm{~V}_{\mathrm{o} 2}}\right|=\left.\sqrt{\frac{\mathrm{C}_{2} \mathrm{~g}_{\mathrm{m} 1}}{\mathrm{C}_{1} \mathrm{~g}_{\mathrm{m} 3}}}\right|_{\mathrm{C}_{1}=\mathrm{C}_{2}, \mathrm{~g}_{\mathrm{m} 1}=\mathrm{g}_{\mathrm{m} 3}}=1 \\
\angle \frac{\mathrm{V}_{\mathrm{o} 1}}{\mathrm{~V}_{\mathrm{o} 2}}=90^{\circ}
\end{gathered}
$$

Equations (23) and (24) show that the voltage magnitude ratio of $V_{o 1}$ and $V_{o 2}$ is in unity, and the voltage phase shift of $\mathrm{V}_{\mathrm{o} 1}$ and $\mathrm{V}_{\mathrm{o} 2}$ is $90^{\circ}$. Thus, the proposed first VM QSO has a unity voltage amplitude ratio and a quadrature voltage phase shift. 
Similarly, routine analysis of the VM NBPF circuit (Figure 3a) yielded the following three NBPF responses:

$$
\begin{gathered}
\frac{V_{\text {BP } 4}}{V_{\text {in }}}=\frac{s_{3} g_{m 2} R_{4}}{s^{2} C_{3} C_{4} R_{4}+s C_{3}+g_{m 1} g_{m 3} R_{4}} \\
\frac{V_{\text {BP } 5}}{V_{\text {in }}}=\frac{s_{3} g_{m 2} R_{4}}{s^{2} C_{3} C_{4} R_{4}+s C_{3}+g_{m 1} g_{m 3} R_{4}} \\
\frac{V_{\text {BP } 6}}{V_{\text {in }}}=\left(\frac{s_{3} g_{m 2} R_{4}}{s^{2} C_{3} C_{4} R_{4}+s C_{3}+g_{m 1} g_{m 3} R_{4}}\right)\left(1+\frac{R_{5}}{R_{6}}\right)
\end{gathered}
$$

Based on three NBPF responses of Equations (25)-(27), the $\mathrm{f}_{\mathrm{o}}, \mathrm{Q}, \mathrm{H}_{\mathrm{BP} 4}, \mathrm{H}_{\mathrm{BP} 5}$ and $\mathrm{H}_{\mathrm{BP} 6}$ are given by

$$
\begin{gathered}
\mathrm{f}_{\mathrm{O}}=\frac{1}{2 \pi} \sqrt{\frac{\mathrm{g}_{\mathrm{m} 1} \mathrm{~g}_{\mathrm{m} 3}}{\mathrm{C}_{3} \mathrm{C}_{4}}} \\
\mathrm{Q}=\mathrm{R}_{4} \sqrt{\frac{\mathrm{C}_{4} \mathrm{~g}_{\mathrm{m} 1} \mathrm{~g}_{\mathrm{m} 3}}{\mathrm{C}_{3}}} \\
\mathrm{H}_{\mathrm{BP} 4}=\mathrm{H}_{\mathrm{BP} 5}=\mathrm{g}_{\mathrm{m} 2} \mathrm{R}_{4} \\
\mathrm{H}_{\mathrm{BP} 6}=\mathrm{g}_{\mathrm{m} 2} \mathrm{R}_{4}\left(1+\frac{\mathrm{R}_{5}}{\mathrm{R}_{6}}\right)
\end{gathered}
$$

From Equations (28)-(31), the NBPF parameters of $f_{o}$ and $Q$ have orthogonal tunability, and the passband gains are independently adjustable by $\mathrm{g}_{\mathrm{m} 2}$ without affecting the NBPF parameters $f_{o}$ and $Q$. Note that the resistors $R_{5}$ and $R_{6}$ in Equation (31) can independently achieve a wide range of NBPF adjustable passband gain without affecting the NBPF parameters $\mathrm{f}_{\mathrm{O}}$ and $\mathrm{Q}$.

By feeding back the input signal to the output response of the VM NBPF as in Figure 3a, a VM fully uncoupled QSO can be realized as shown in Figure $3 \mathrm{~b}$. This means that the input signal $V_{\text {in }}$ is connected to $V_{B P 4}$ (Figure 3a), and Equation (25) becomes

$$
\left.\frac{V_{\mathrm{BP} 4}}{V_{\text {in }}}\right|_{V_{\mathrm{BP} 4}=V_{\text {in }}}=1=\frac{\mathrm{sC}_{3} \mathrm{~g}_{\mathrm{m} 2} \mathrm{R}_{4}}{\mathrm{~s}^{2} \mathrm{C}_{3} \mathrm{C}_{4} \mathrm{R}_{4}+\mathrm{s} \mathrm{C}_{3}+\mathrm{g}_{\mathrm{m} 1} \mathrm{~g}_{\mathrm{m} 3} \mathrm{R}_{4}}
$$

Therefore, the CE from Figure $3 \mathrm{~b}$ is expressed as

$$
\mathrm{s}^{2} \mathrm{C}_{3} \mathrm{C}_{4} \mathrm{R}_{4}+\mathrm{sC}_{3}\left(1-\mathrm{g}_{\mathrm{m} 2} \mathrm{R}_{4}\right)+\mathrm{g}_{\mathrm{m} 1} \mathrm{~g}_{\mathrm{m} 3} \mathrm{R}_{4}=0
$$

Based on Equation (33), the CO and FO of the proposed VM QSO (Figure $3 b$ ) are given by Equations (34) and (35), respectively:

$$
\begin{gathered}
\text { CO: } g_{m 2} R_{4} \geq 1 \\
\text { FO : } f_{o}=\frac{1}{2 \pi} \sqrt{\frac{g_{m 1} g_{m 3}}{C_{3} C_{4}}}
\end{gathered}
$$

According to Equations (34) and (35), the CO can be fully controlled independently without affecting the $\mathrm{FO}$ by adjusting $\mathrm{g}_{\mathrm{m} 2}$ or $\mathrm{R}_{4}$, and the $\mathrm{FO}$ can also be fully controlled independently without affecting the CO by adjusting $\mathrm{g}_{\mathrm{m} 1}$ or $\mathrm{g}_{\mathrm{m} 3}$. Hence, the VM QSO shown in Figure $3 \mathrm{~b}$ provides a fully uncoupled tuning law for the $\mathrm{CO}$ and FO. Routine analysis of the VM QSO structure (Figure 3b) yielded the following two quadrature voltage outputs and a sinusoidal output waveform with independent amplitude control:

$$
\frac{V_{04}}{V_{o 5}}=\left.\frac{g_{m 1}}{s C_{3}}\right|_{s=j \omega_{o}}=\frac{g_{m 1}}{\omega_{o} C_{3}} e^{-j 90^{\circ}}=\sqrt{\frac{C_{4} g_{m 1}}{C_{3} g_{m 3}}} e^{-j 90^{\circ}}
$$




$$
\mathrm{V}_{\mathrm{o} 6}=\left(1+\frac{\mathrm{R}_{5}}{\mathrm{R}_{6}}\right) \mathrm{V}_{\mathrm{o} 5}
$$

According to Equation (36), the magnitude ratio and phasor of output voltages $V_{04}$ and $\mathrm{V}_{\mathrm{o} 5}$ are given as

$$
\begin{gathered}
\left|\frac{\mathrm{V}_{\mathrm{o} 4}}{\mathrm{~V}_{\mathrm{o} 5}}\right|=\left.\sqrt{\frac{\mathrm{C}_{4} \mathrm{~g}_{\mathrm{m} 1}}{\mathrm{C}_{3} \mathrm{~g}_{\mathrm{m} 3}}}\right|_{\mathrm{C}_{3}=\mathrm{C}_{4}, \mathrm{~g}_{\mathrm{m} 1}=\mathrm{g}_{\mathrm{m} 3}}=1 \\
\angle \frac{\mathrm{V}_{\mathrm{o} 4}}{\mathrm{~V}_{\mathrm{o} 5}}=-90^{\circ}
\end{gathered}
$$

Equations (38) and (39) show that the voltage magnitude ratio of $V_{04}$ and $V_{05}$ is in unity, and the voltage phase shift of $\mathrm{V}_{\mathrm{o} 4}$ and $\mathrm{V}_{\mathrm{o}}$ is $-90^{\circ}$. Thus, the proposed second $\mathrm{VM}$ QSO has a unity voltage amplitude ratio and a quadrature voltage phase shift.

\section{Simulation and Experimental Measurements}

The proposed isomorphic circuits of the VM NBPFs and VM QSOs were simulated with Cadence OrCAD PSpice simulation software version 16.6 to confirm the theory and implemented by three off-the-shelf LT1228 ICs, two grounded capacitors and three resistors to verify the performance of the isomorphic circuits. The isomorphic circuits adopted a DC bias of $\pm 5 \mathrm{~V}$ for the voltage supplies, and the voltage output was measured in the time domain with a Tektronix DPO 2048B oscilloscope, the voltage output was measured in the frequency domain with a Keysight E5061B-3L5 network analyzer, and the voltage output in the frequency spectrum was measured with a Keysight-Agilent N9000A CXA signal analyzer. The measurement photos of the isomorphic circuits are shown in Figures 4 and 5.

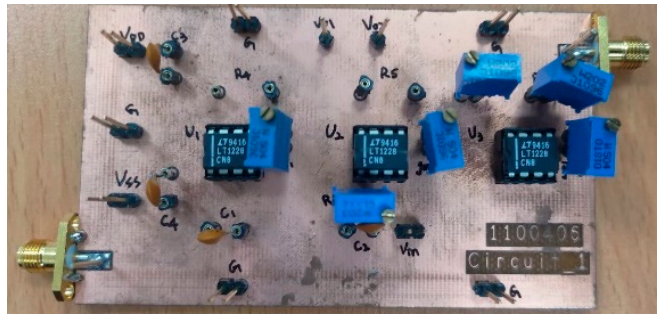

(a)

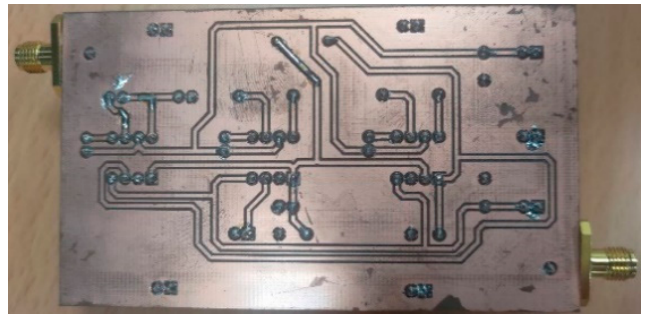

(b)

Figure 4. The (a) top view and (b) bottom view of the measured prototype from Figure 2.

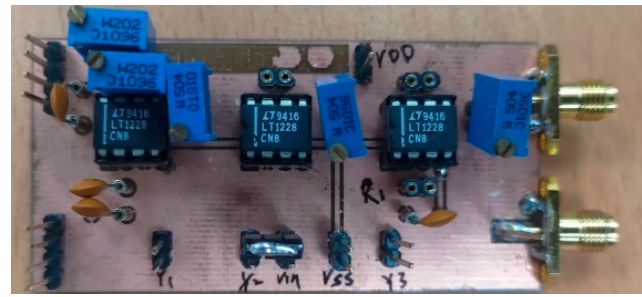

(a)

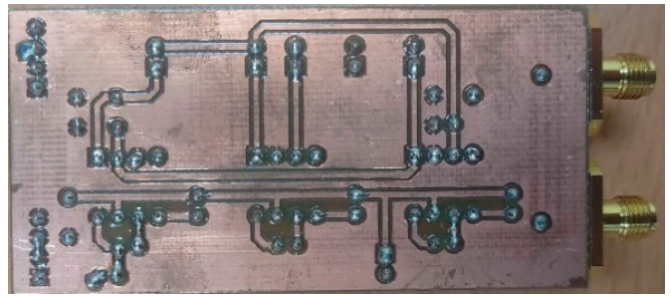

(b)

Figure 5. The (a) top view and (b) bottom view of the measured prototype from Figure 3.

\subsection{First Proposed Isomorphic Circuit Simulation and Experimental Results}

The theoretical, simulated and measured NBPF responses of $\mathrm{V}_{\mathrm{BP} 2}$ and $\mathrm{V}_{\mathrm{BP} 3}$ (Figure 2a) are shown in Figures 6 and 7, respectively, as depicted in Equations (11) and (12). In Figure 6, the NBPF voltage gain at the voltage output of $\mathrm{V}_{\mathrm{BP} 2}$ could be adjusted independently by $g_{m 2}$ without affecting parameters $f_{o}$ and $Q$, as depicted in Equations (13)-(15). In Figure 7, the wide range of independent amplitude adjustable NBPF voltage gain at the voltage output of $\mathrm{V}_{\mathrm{BP} 3}$ could also be independently adjusted by $\mathrm{R}_{2}$ without affecting the NBPF parameters $f_{O}$ and $Q$, as depicted in Equations (13), (14) and (16). The component values used in Figure 6 were $C_{1}=C_{2}=0.96 \mathrm{nF}, g_{\mathrm{m} 1}=g_{\mathrm{m} 3}=1 \mathrm{mS}$ and $\mathrm{R}_{1}=\mathrm{R}_{2}=\mathrm{R}_{3}=1 \mathrm{k} \Omega$ 
for the theoretical value of $\mathrm{f}_{\mathrm{o}}=165.8 \mathrm{kHz}$, and only $\mathrm{g}_{\mathrm{m} 2}$ changed, with different values of 1 , $1.5,2$ and $3 \mathrm{mS}$. This resulted in an NBPF at a voltage output of $\mathrm{V}_{\mathrm{BP} 2}$ with voltage gains of 0, 3.52, 6.02 and $9.54 \mathrm{~dB}$. Figure 8 shows the measurement results of the $\mathrm{V}_{\mathrm{BP} 2}$ gain response. The component values used in Figure 7 were $C_{1}=C_{2}=0.96 \mathrm{nF}, g_{\mathrm{m} 1}=g_{\mathrm{m} 2}=g_{\mathrm{m} 3}=1 \mathrm{mS}$ and $R_{1}=R_{3}=1 \mathrm{k} \Omega$ for a theoretical value of $f_{o}=165.8 \mathrm{kHz}$, and only $R_{2}$ changed, with different values of $1,4,11$ and $19 \mathrm{k} \Omega$. This resulted in an NBPF at a voltage output of $\mathrm{V}_{\mathrm{BP} 3}$ with voltage gains of $6.02,13.98,21.58$ and $26 \mathrm{~dB}$. Figure 9 shows the measurement results of the $\mathrm{V}_{\mathrm{BP} 3}$ gain response. To display the independent electronically adjusted passband gains from Figure $2 \mathrm{a}$, the value of $\mathrm{g}_{\mathrm{m} 2}$ was changed from $1 \mathrm{mS}$ to $4 \mathrm{mS}$, and the NBPF voltage gain at the voltage output of $\mathrm{V}_{\mathrm{BP} 2}$ could be changed from $0 \mathrm{~dB}$ to $12.04 \mathrm{~dB}$. As shown in Figure 10, the proposed NBPF in Figure 2a exhibited independent electronic adjustment of passband gains at the voltage output of $\mathrm{V}_{\mathrm{BP} 2}$. To display the maximum operating passband gains of Figure $2 a$, the value of $R_{2}$ was changed from $1 \mathrm{k} \Omega$ to $25 \mathrm{k} \Omega$, and the NBPF voltage gain at the voltage output of $\mathrm{V}_{\mathrm{BP} 3}$ could be changed from $6.02 \mathrm{~dB}$ to $28.3 \mathrm{~dB}$. As is shown in Figure 11, the proposed NBPF from Figure 2a exhibited a wide range of independent amplitude adjustable passbands at a voltage output of $\mathrm{V}_{\mathrm{BP} 3}$. Figure 12 shows the theoretical, simulated and measured NBPF responses on the $\mathrm{V}_{\mathrm{BP} 2}$ output terminal with different values of $R_{1}$ when $C_{1}=C_{2}=0.96 \mathrm{nF}, R_{2}=R_{3}=1 \mathrm{k} \Omega$ and $g_{\mathrm{m} 1}=g_{\mathrm{m} 2}=g_{\mathrm{m} 3}=1 \mathrm{mS}$. Figure 13 shows the measurement results of the $\mathrm{V}_{\mathrm{BP} 2}$ gain response with different $\mathrm{Q}$ values. In this case, the four values of $R_{1}$ were changed to $1,1.5,2$ and $3 \mathrm{k} \Omega$, and the measured values of $Q$ were 1.17, 1.53, 2.08 and 3. As shown in Figures 12 and 13, the $Q$ parameter of the NBPF could be independently controlled by adjusting the different values of $R_{1}$ without affecting the parameters of $f_{O}$, as depicted in Equations (13) and (14). For an experimental test, Figure 14 shows the input and output voltage waveforms of the NBPF response at the $V_{\mathrm{BP} 2}$ output terminal, which could be extended to an amplitude of $120 \mathrm{mVpp}$ without signification distortion. As shown in Figure 14, the input voltage waveform was a 165.8-kHz sinusoidal waveform, and the output voltage waveform was measured to be a $161.7-\mathrm{kHz}$ sinusoidal waveform with a phase difference of $0.23^{\circ}$.

To evaluate the performance of the proposed isomorphic circuit, the total harmonic distortion (THD) and the intermodulation distortion (IMD) of the isomorphic circuit were measured. The THD is defined as the ratio of the sum of the powers of all harmonic components (except the fundamental frequency) to the power of fundamental frequency. The IMD is defined as the two-tone test signals of different frequencies mixed together to form an additional signal at the excitation frequency. The THD and IMD can be expressed as follows $[26,27]$ :

$$
\operatorname{THD}=\sqrt{\frac{\sum_{\mathrm{n}=2}^{\mathrm{N}} \mathrm{V}_{\mathrm{n}}^{2}}{\mathrm{~V}_{1}^{2}}} \times 100 \%
$$

where $V_{1}$ is the fundamental frequency voltage content and $V_{n}(n=2,3, \ldots, N)$ is the nth harmonic voltage content:

$$
\operatorname{IMD}\left(\mathrm{f}_{1}, \mathrm{f}_{2}\right)=\frac{\sum_{\mathrm{k}=1}^{2} \mathrm{p}\left(\mathrm{f}_{2}-\mathrm{kf}_{1}\right)+\mathrm{p}\left(\mathrm{f}_{2}+\mathrm{kf}_{1}\right)}{\mathrm{p}\left(\mathrm{f}_{2}\right)} \times 100 \%
$$

where $\mathrm{p}\left(\mathrm{f}_{2} \pm(\mathrm{n}-1)\right) \mathrm{f}_{1}$ is the root mean square value of the nth-order intermodulation component at the sum and difference of the two tones and $p\left(f_{2}\right)$ is the root mean square value of the fundamental component at the excitation frequency $f_{2}$. Figure 15 shows the frequency spectrum of the NBPF response at the $\mathrm{V}_{\mathrm{BP} 2}$ output terminal. The NBPF response center frequency measured at the output of $\mathrm{V}_{\mathrm{BP} 2}$ was about $165.8 \mathrm{kHz}$. The THD, including the fundamental harmonic through the sixth harmonic components of Figure 15, was about $1.08 \%$. Figure 16 shows the THD result of the NBPF response at the $\mathrm{V}_{\mathrm{BP} 2}$ output terminal with different input voltages by keeping a constant center frequency of $165.8 \mathrm{kHz}$. 
Figure 17 shows the spectrum of the NBPF at the output of $\mathrm{V}_{\mathrm{BP} 2}$, which was obtained by applying two-tone signals $\mathrm{f}_{1}$ and $\mathrm{f}_{2}$ around the theoretical value of $\mathrm{f}_{\mathrm{o}}=165.8 \mathrm{kHz}$ for IMD characterization. In Figure 17, the low-frequency tones of $f_{1}=164.8 \mathrm{kHz}$ and the high-frequency tones of $f_{2}=166.8 \mathrm{kHz}$ were used with an input amplitude of $63 \mathrm{mVpp}$. The measured value of the third-order IMD (IMD3) was about $-40.1 \mathrm{dBc}$, and the thirdorder intercept (TOI) was about $-7.95 \mathrm{dBm}$. Figure 18 shows the $1-\mathrm{dB}$ compression point (P1dB) of the NBPF measured at the output of $\mathrm{V}_{\mathrm{BP} 2}$ between the output power and the input power when the center frequency was $165.8 \mathrm{kHz}$. The measured output power P1dB was about $-11.4 \mathrm{dBm}$. Figure 19 shows the phase noise performance of the NBPF measured at the output of $\mathrm{V}_{\mathrm{BP} 2}$. The measured value of the phase noise of $\mathrm{V}_{\mathrm{BP} 2}$ was less than $-83.86 \mathrm{dBc} / \mathrm{Hz}$ at a $30-\mathrm{Hz}$ offset.

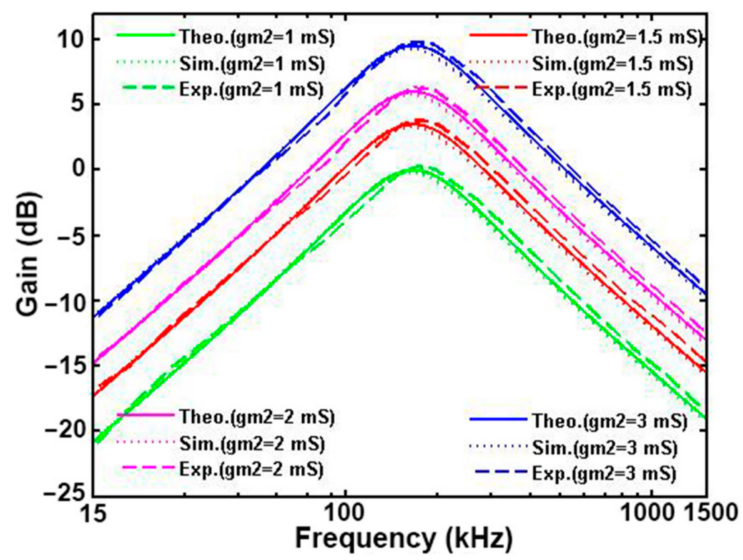

Figure 6. The theoretical, simulated and measured NBPF responses at the voltage output of $\mathrm{V}_{\mathrm{BP} 2}$ when $g_{\mathrm{m} 2}$ was varied.

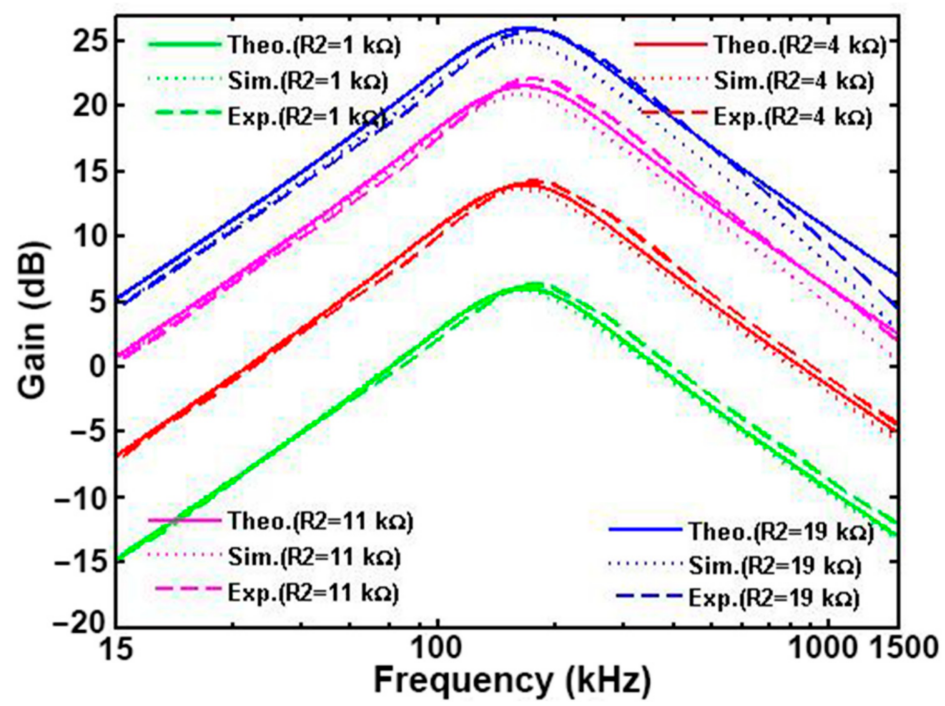

Figure 7. The theoretical, simulated and measured NBPF responses at the voltage output of $\mathrm{V}_{\mathrm{BP} 3}$ when $R_{2}$ was varied. 


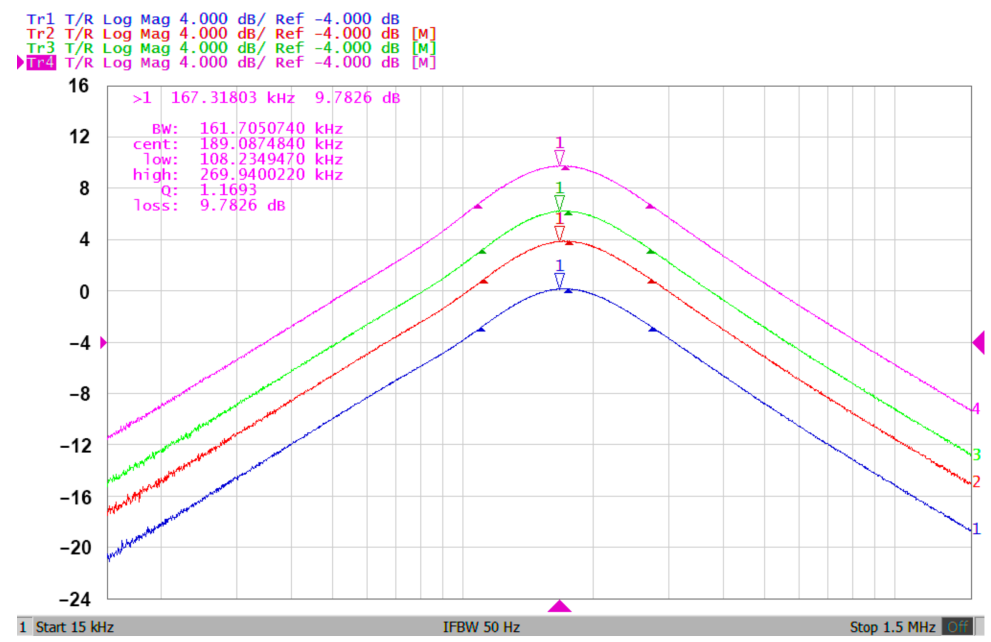

Figure 8. The measured magnitude responses of the $V_{B P 2}$ when $g_{m 2}$ was varied.

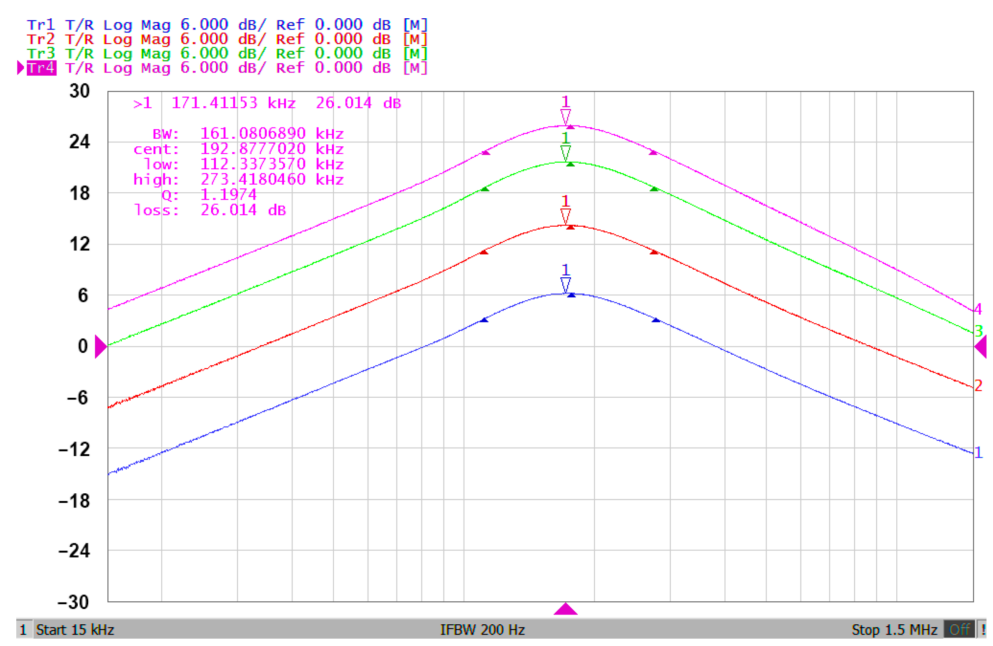

Figure 9. The measured magnitude responses of the $V_{B P 3}$ when $R_{2}$ was varied.

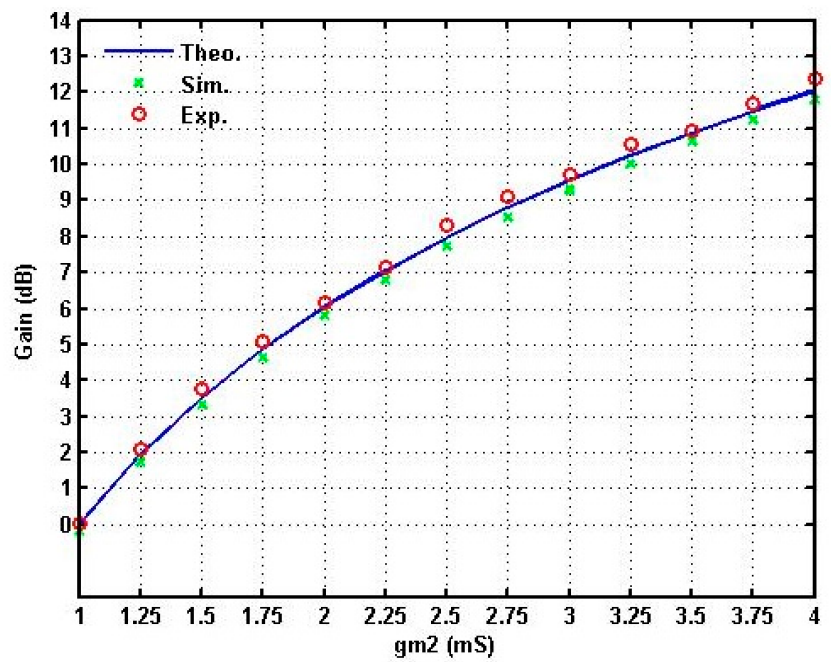

Figure 10. The theoretical, simulated and measured results of the electronic amplitude adjustable NBPF voltage gains at the voltage output of $\mathrm{V}_{\mathrm{BP} 2}$. 


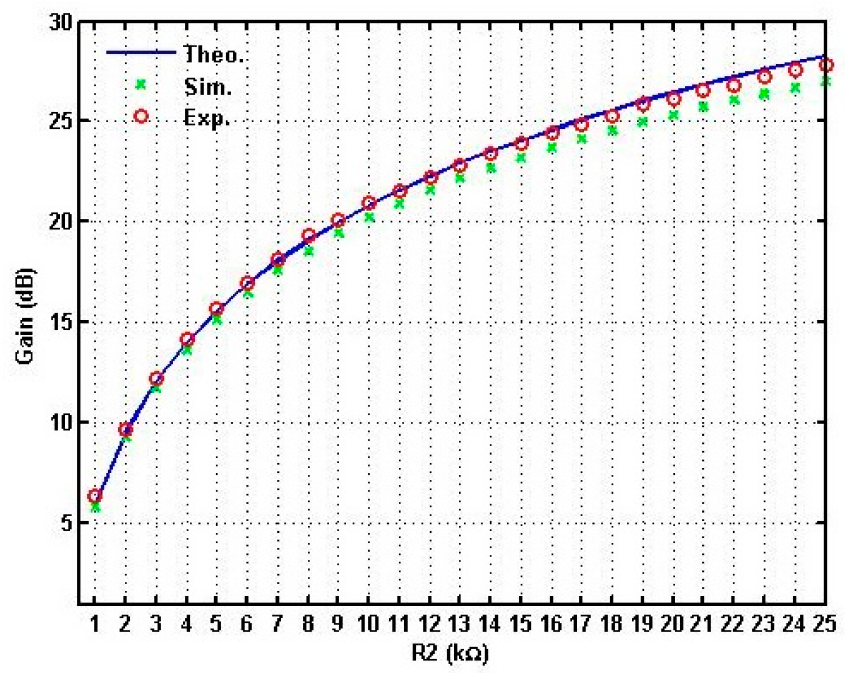

Figure 11. The theoretical, simulated and measured results of the independent amplitude adjustable $\mathrm{NBPF}$ voltage gains at the voltage output of $\mathrm{V}_{\mathrm{BP} 3}$.

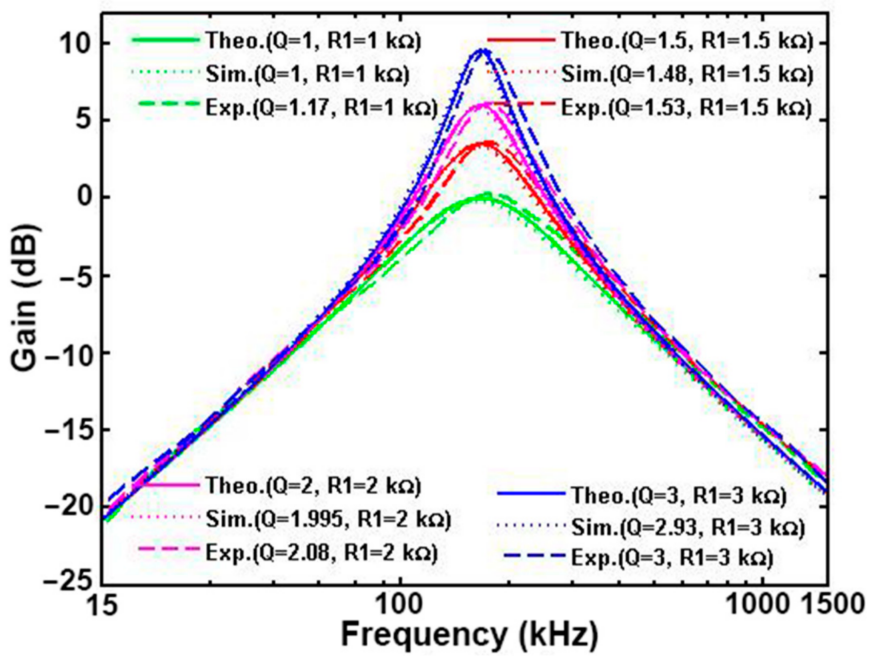

Figure 12. The $Q$ parameters of the NBPF at the output of $V_{B P 2}$ by varying $R_{1}$ while maintaining $f_{O}$.

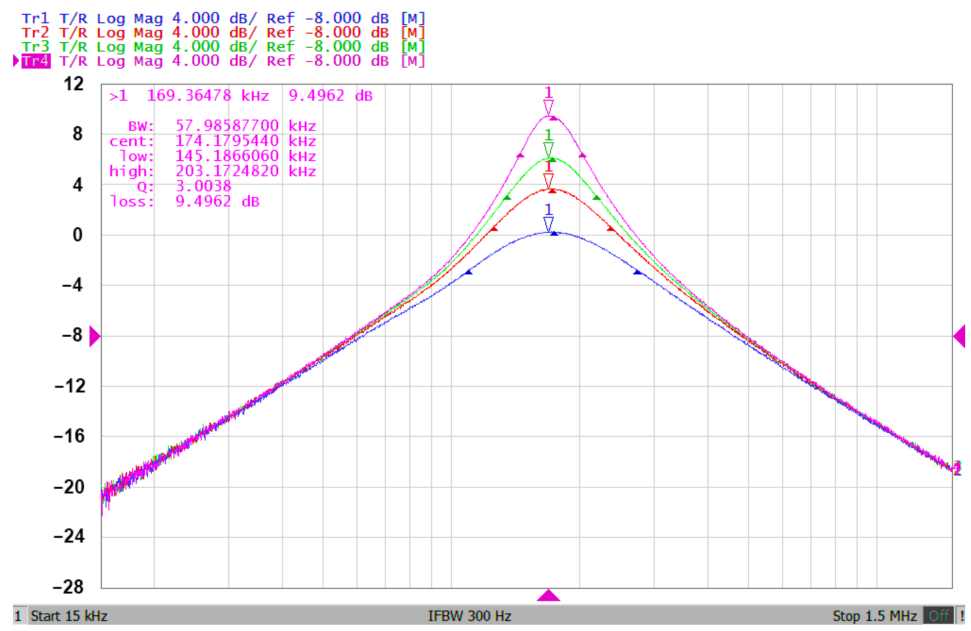

Figure 13. The measured magnitude responses of the $V_{B P 2}$ with different $Q$ values by varying $R_{1}$ while maintaining $f_{0}$. 


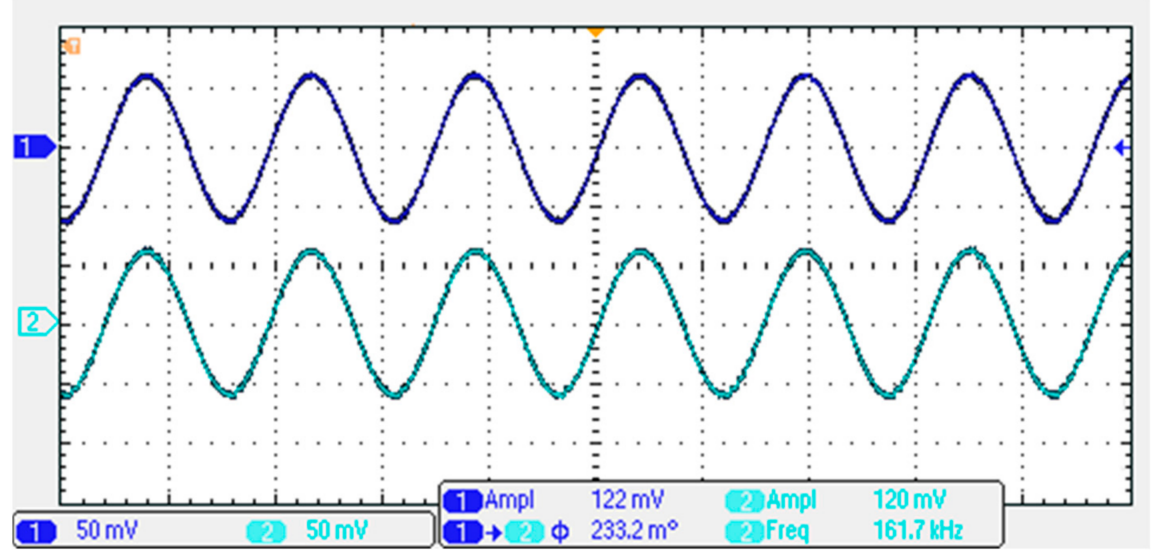

Figure 14. The measured time domain input and output voltage waveforms of the NBPF at the output of $\mathrm{V}_{\mathrm{BP} 2}$.

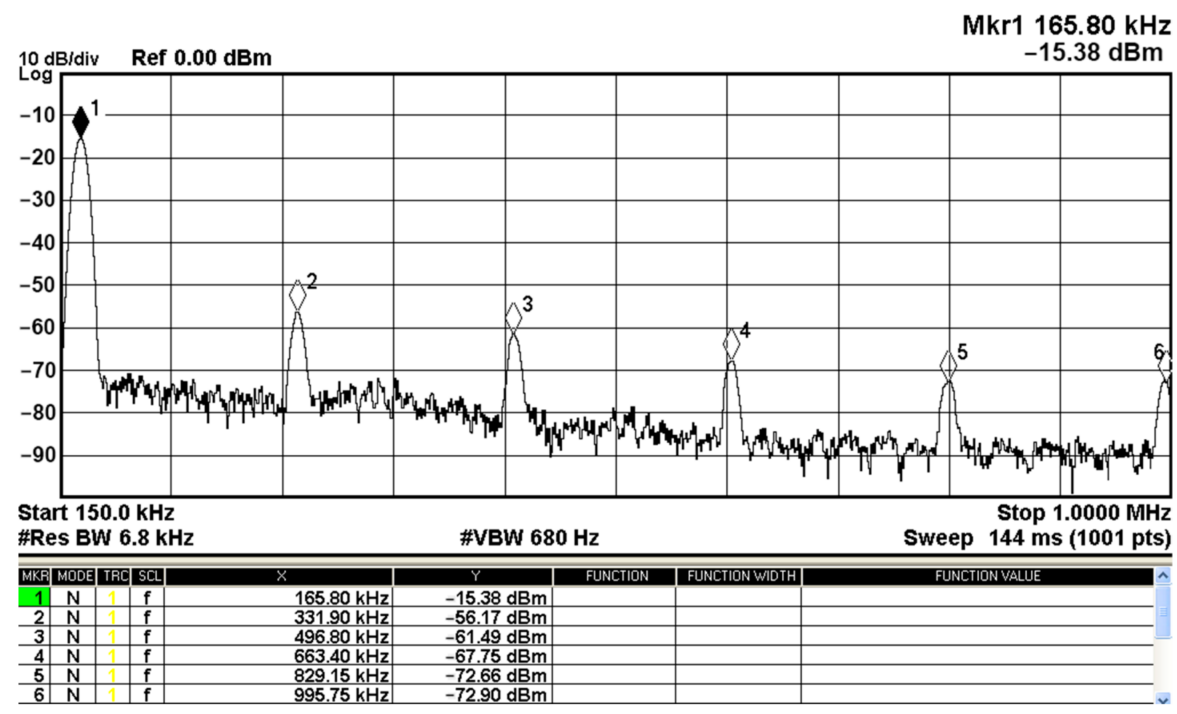

Figure 15. The frequency spectrum results of the NBPF at the output of $\mathrm{V}_{\mathrm{BP} 2}$.

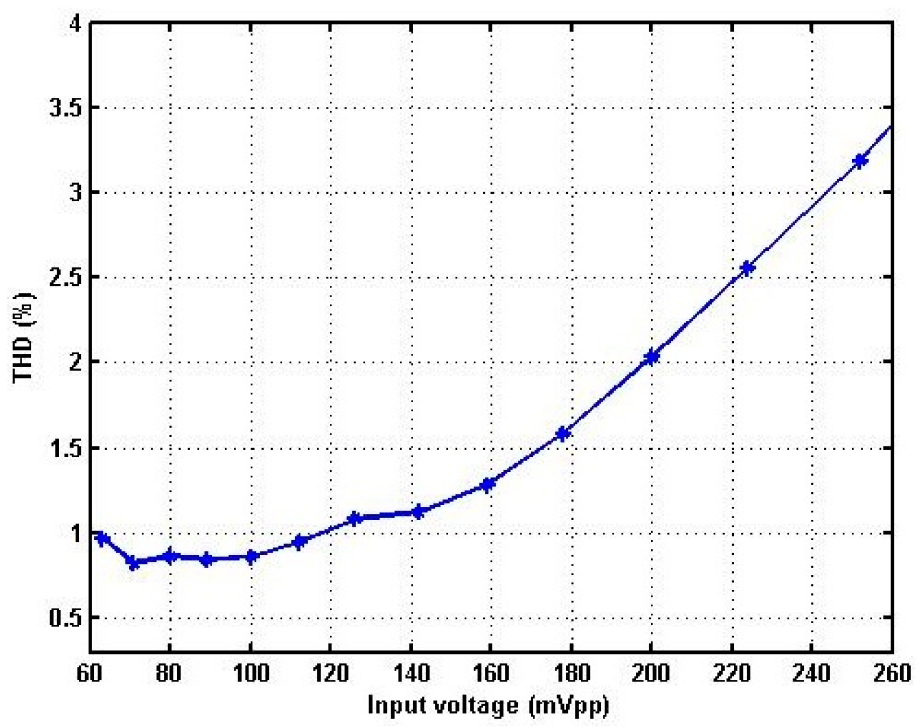

Figure 16. THD analysis results of the NBPF at the output of $\mathrm{V}_{\mathrm{BP} 2}$ with different input voltages. 


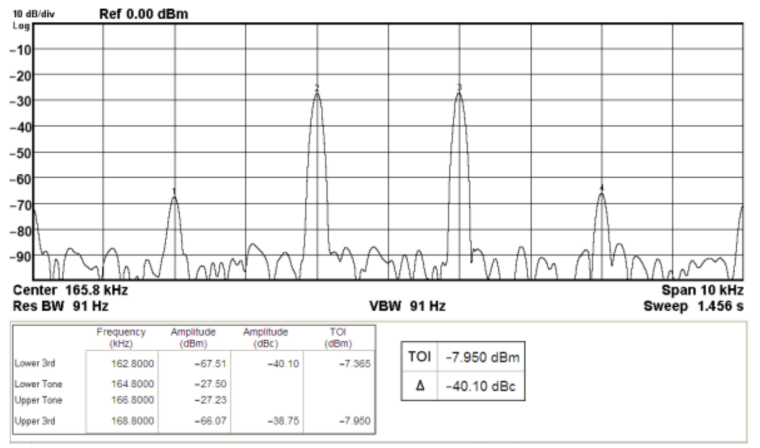

Figure 17. The NBPF at the $\mathrm{V}_{\mathrm{BP} 2}$ output spectrum for a two-tone intermodulation distortion test.

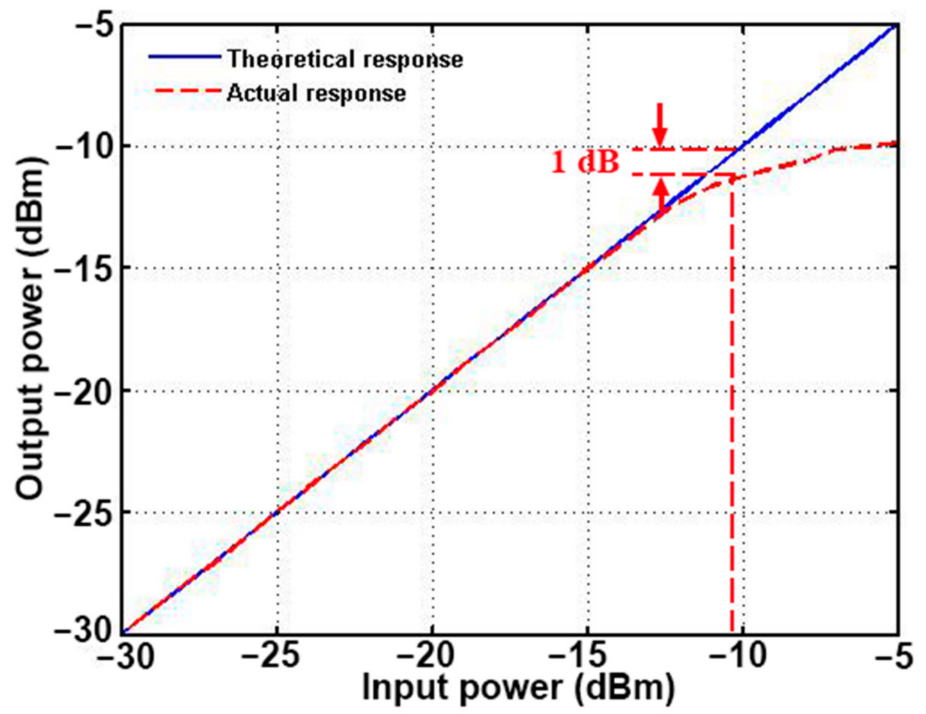

Figure 18. The measured P1dB of the NBPF at $V_{B P 2}$ with the input power when $\mathrm{f}_{\mathrm{O}}$ was $165.8 \mathrm{kHz}$.

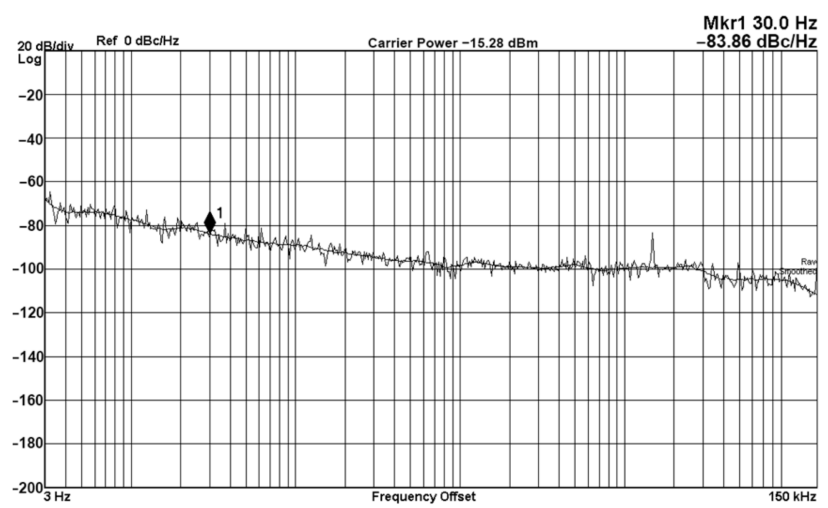

Figure 19. The measured phase noise performance of the NBPF at $V_{\mathrm{BP} 2}$.

The figure of merit (FoM) of the filter can be defined as [28]

$$
\text { FoM }=\frac{\text { Dynamic range } \times \mathrm{f}_{\mathrm{o}}}{\text { Power dissipation } \times \text { Supply voltage }}
$$

According the NBPF frequency spectrum measured in Figure 15, the dynamic range between the fundamental tone and the largest spurious of the spurious-free dynamic range was approximately $40.79 \mathrm{~dB}$. Thus, the FoM of the proposed VM NBPF at the voltage output of $\mathrm{V}_{\mathrm{BP} 2}$ was approximately computed to be $3.07 \times 10^{6}$. 
To investigate the VM fully uncoupled QSO in Figure 2b, Figure 20 shows the measured waveforms of the quadrature voltage outputs $\mathrm{V}_{\mathrm{o} 1}$ and $\mathrm{V}_{\mathrm{o} 2}$ in the time domain. The component values used in Figure 20 were $C_{1}=C_{2}=0.96 \mathrm{nF}, \mathrm{g}_{\mathrm{m} 1}=\mathrm{g}_{\mathrm{m} 2}=\mathrm{g}_{\mathrm{m} 3}=1 \mathrm{mS}$ and $R_{1}=R_{2}=R_{3}=1 \mathrm{k} \Omega$ for the theoretical value of $f_{o}=165.8 \mathrm{kHz}$. The measured FO in Figure 20 was $162.3 \mathrm{kHz}$, which was close to the theoretical value of $165.8 \mathrm{kHz}$. Figure 21 shows the spectrum of the VM fully uncoupled QSO at the $\mathrm{V}_{\mathrm{o} 2}$ output terminal. The measured FO was $160.95 \mathrm{kHz}$, which was close to the theoretical value of $165.8 \mathrm{kHz}$. The difference between the amplitudes of the fundamental and second harmonics was 41.87 $\mathrm{dB}$, and the calculated THD was about $0.81 \%$. As shown in Figure 21, the third harmonic and subsequent harmonics were not visible in the spectrum because these harmonics were lower than the noise floor. This means that the THD of the first proposed VM fully uncoupled QSO was small. Figure 22 shows the phase noise performance of the QSO measured at the output of $\mathrm{V}_{\mathrm{O} 2}$. The measured value of the phase noise of $\mathrm{V}_{\mathrm{O} 2}$ was less than $-40.18 \mathrm{dBc} / \mathrm{Hz}$ at a $30-\mathrm{Hz}$ offset. Figure 23 shows the FO tuning range of the measured output voltage $\mathrm{V}_{\mathrm{o} 2}$, where $\mathrm{C}_{1}=\mathrm{C}_{2}=0.96 \mathrm{nF}, \mathrm{g}_{\mathrm{m} 2}=1 \mathrm{mS}$ and $\mathrm{R}_{1}=\mathrm{R}_{2}=\mathrm{R}_{3}=1 \mathrm{k} \Omega$, and only $g_{\mathrm{m} 1}=g_{\mathrm{m} 3}$ were varied from the values of $0.5-10 \mathrm{mS}$. As is shown in Figure 23 , the measured oscillation frequency was electronically and linearly varied from $82.15 \mathrm{kHz}$ to $1629 \mathrm{kHz}$. In Figures 20-23, the $\mathrm{g}_{\mathrm{m} 2}$ value should have been slightly adjusted to satisfy the $\mathrm{CO}$ as depicted in Equation (19). Figure 24 shows the relationship between the measured amplitude ratio of the quadrature output voltages $\mathrm{V}_{\mathrm{o} 1}$ and $\mathrm{V}_{\mathrm{o} 2}$ and the $\mathrm{FO}$ as depicted in Equation (23). Figure 25 shows the relationship between the measured phase difference of the quadrature output voltages $\mathrm{V}_{\mathrm{o} 1}$ and $\mathrm{V}_{\mathrm{O} 2}$ and the $\mathrm{FO}$ as depicted in Equation (24). Figure 26 shows the experimental results of the voltage gain of $V_{03}$ when only $R_{2}$ was changed while maintaining $C_{1}=C_{2}=0.96 \mathrm{nF}, \mathrm{g}_{\mathrm{m} 1}=\mathrm{g}_{\mathrm{m} 2}=\mathrm{g}_{\mathrm{m} 3}=1 \mathrm{mS}, \mathrm{g}_{\mathrm{m} 2}=1.05 \mathrm{mS}$ and $R_{1}=R_{3}=1 \mathrm{k} \Omega$. As is shown in Figure 26, the proposed VM fully uncoupled QSO (Figure $2 b$ ) exhibited a wide range of independent amplitude adjustable $V_{\mathrm{o} 3}$ voltage gains. The measured operating amplitude control range could be adjusted from 1.51 to 24.05. Table 4 summarizes the performance of the first proposed isomorphic circuit.

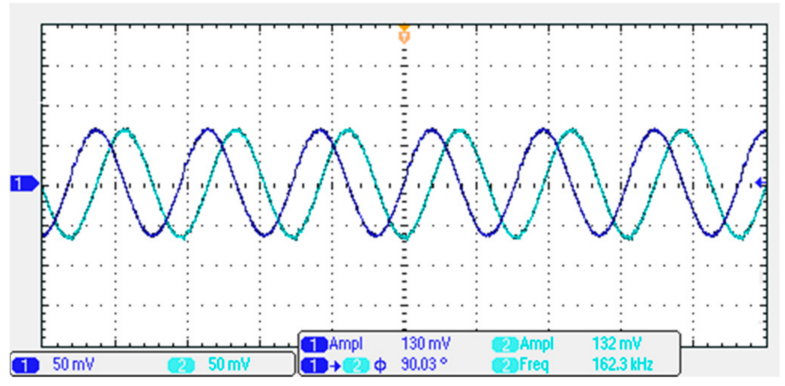

Figure 20. The measured waveforms of the quadrature voltage outputs $V_{\mathrm{o} 1}$ and $\mathrm{V}_{\mathrm{o} 2}$ in the time domain.

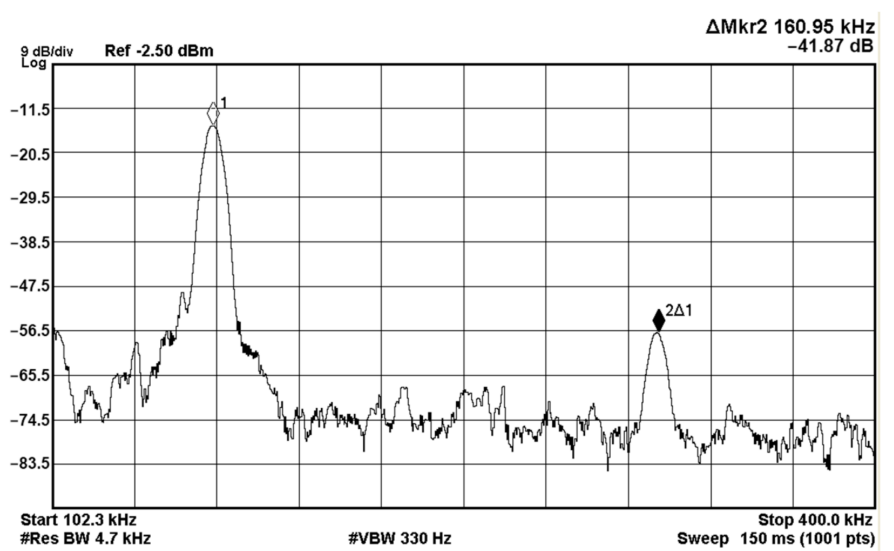

Figure 21. The frequency spectrum results of the VM fully uncoupled QSO at the $\mathrm{V}_{\mathrm{o} 2}$ output terminal. 


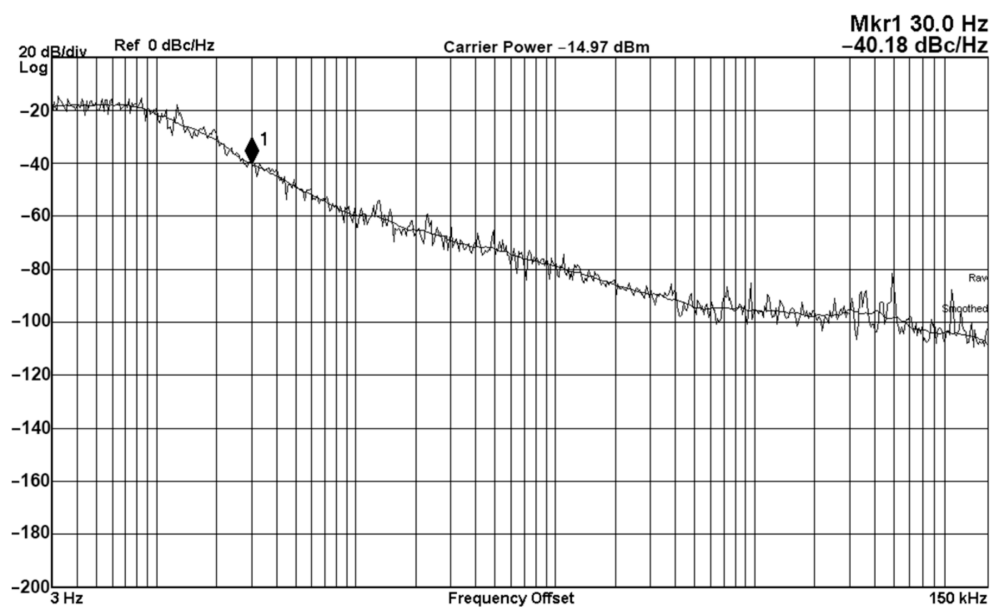

Figure 22. The measured phase noise performance of the VM QSO at the $\mathrm{V}_{\mathrm{o} 2}$ output terminal.

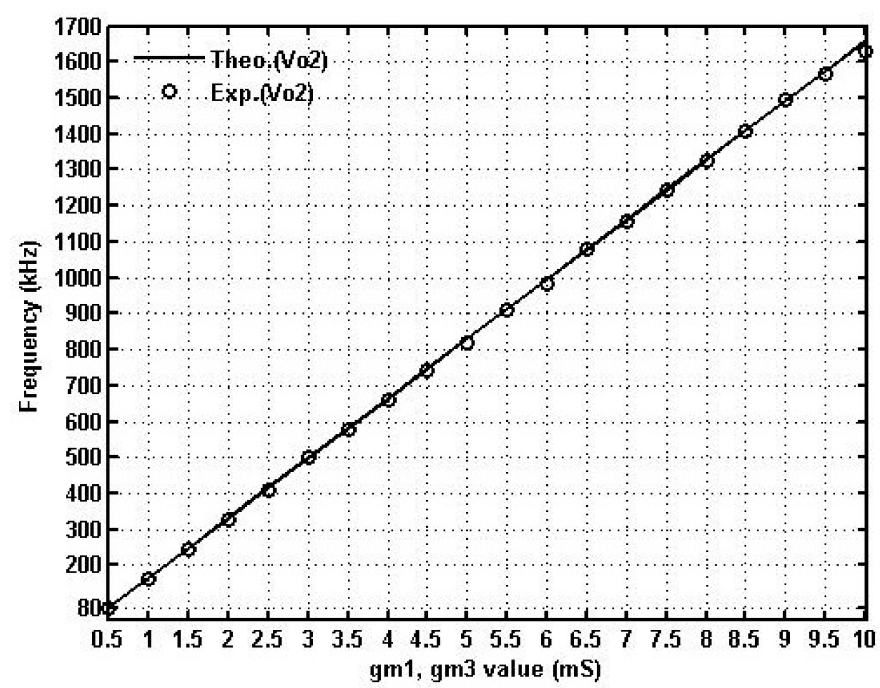

Figure 23. The experimental results of $V_{\mathrm{o} 2}$ for $g_{\mathrm{m} 1}=g_{\mathrm{m} 3}$.

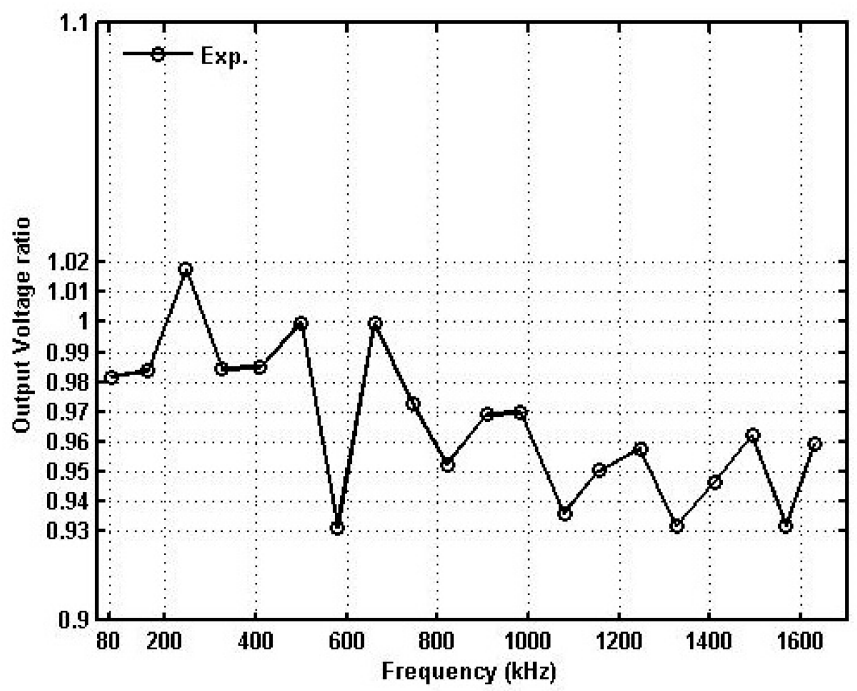

Figure 24. The measured amplitude ratio of the quadrature output voltages $\mathrm{V}_{\mathrm{o} 1}$ and $\mathrm{V}_{\mathrm{o} 2}$ versus the tuning FO. 


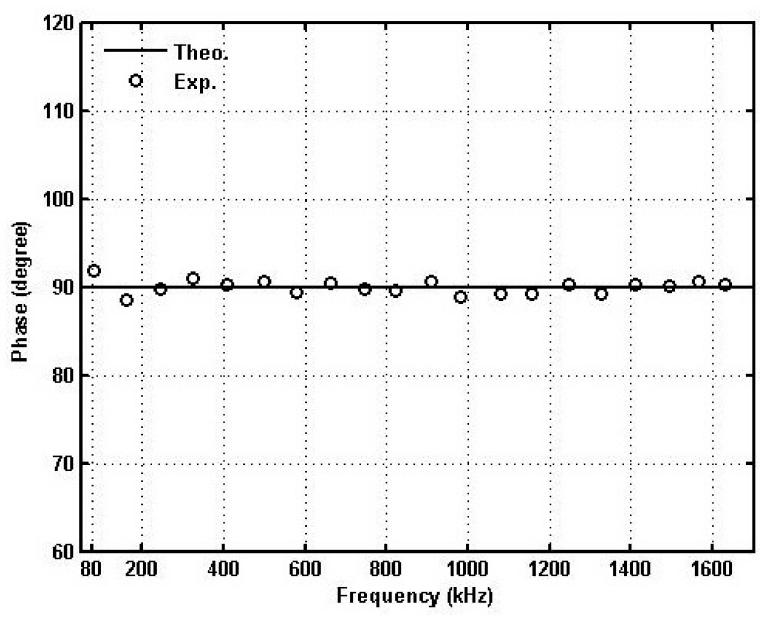

Figure 25. The measured phase difference of quadrature output voltages $\mathrm{V}_{\mathrm{o} 1}$ and $\mathrm{V}_{\mathrm{O} 2}$ versus the tuning FO.

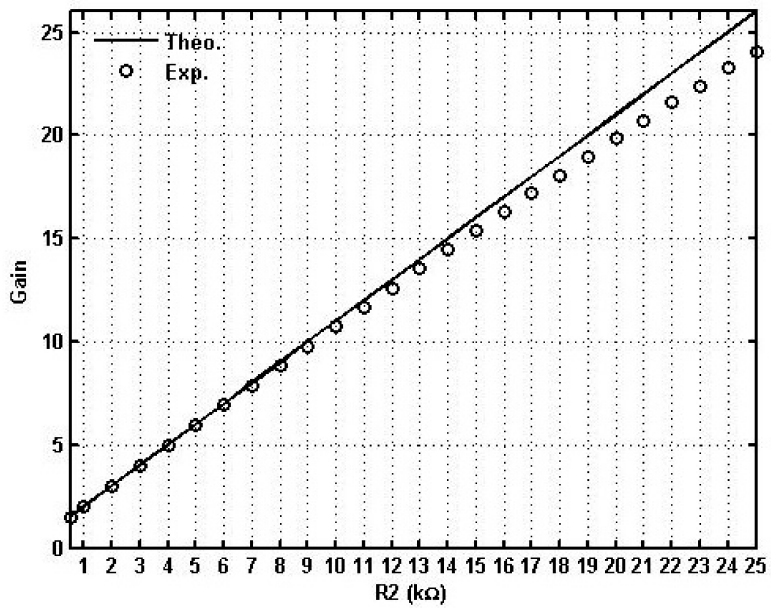

Figure 26. The experimental results of the $V_{03}$ voltage gain when $R_{2}$ was varied.

Table 4. Performance parameters of the performance of the first proposed isomorphic circuit.

\begin{tabular}{|c|c|}
\hline \multicolumn{2}{|l|}{ Non-Inverting Bandpass Filter Factor } \\
\hline Supply voltage (V) & \pm 5 \\
\hline Power dissipation (W, measurement) & 0.22 \\
\hline Central frequency (kHz, design/measurement) & $165.8 / 161.7$ \\
\hline Maximum operating voltage gain (dB, design/measurement) & $28.3 / 27.86$ \\
\hline Measured total harmonic distortion at $\mathrm{V}_{\text {in }}=120 \mathrm{mV}_{\mathrm{PP}}(\%)$ & 1.08 \\
\hline Measured output 1-dB compression point $(\mathrm{dBm})$ & -11.4 \\
\hline Measured third-order intermodulation distortion at $63 \mathrm{mV}_{\mathrm{PP}}(\mathrm{dBc})$ & -40.1 \\
\hline Measured third-order intercept point $(\mathrm{dBm})$ & -7.95 \\
\hline Measured phase noise at $30 \mathrm{~Hz}(\mathrm{dBc} / \mathrm{Hz})$ & -83.86 \\
\hline Measured spurious-free dynamic range $(\mathrm{dB})$ & 40.79 \\
\hline Figure of merit & $3.07 \times 10^{6}$ \\
\hline \multicolumn{2}{|l|}{ Fully Uncoupled Quadrature Oscillator Factor } \\
\hline Supply voltage $(\mathrm{V})$ & \pm 5 \\
\hline Power dissipation (W, measurement) & 0.22 \\
\hline Number of sinusoidal voltage output used & 3 \\
\hline Oscillation frequency (kHz, design/measurement) & $165.8 / 162.3$ \\
\hline Measured total harmonic distortion (\%) & 0.81 \\
\hline Measured phase noise at $30 \mathrm{~Hz}(\mathrm{dBc} / \mathrm{Hz})$ & -40.18 \\
\hline Measured operating oscillation frequency range $(\mathrm{kHz})$ & $82.15 \sim 1629$ \\
\hline Measured operating amplitude control range & $1.51 \sim 24.05$ \\
\hline
\end{tabular}




\subsection{Second Proposed Isomorphic Circuit Simulation and Experimental Results}

The theoretical, simulated and measured NBPF responses of the $\mathrm{V}_{\mathrm{BP} 5}$ and $\mathrm{V}_{\mathrm{BP} 6}$ (Figure 3a) are shown in Figures 27 and 28, respectively, as depicted in Equations (26) and (27). In Figure 27, the NBPF voltage gain at the voltage output of $\mathrm{V}_{\mathrm{BP} 5}$ could be adjusted independently by $g_{m 2}$ without affecting the parameters $f_{O}$ and $Q$ as depicted in Equations (28)-(30). In Figure 28, the wide range of the independent amplitude adjustable NBPF voltage gain at the voltage output of $\mathrm{V}_{\mathrm{BP} 6}$ could also be independently adjusted by $R_{5}$ without affecting the NBPF parameters $f_{o}$ and $Q$ as depicted in Equations (28), (29) and (31). The component values used in Figure 27 were $C_{3}=C_{4}=0.96 \mathrm{nF}, \mathrm{g}_{\mathrm{m} 1}=\mathrm{g}_{\mathrm{m} 3}=1 \mathrm{mS}$ and $R_{4}=R_{5}=R_{6}=1 \mathrm{k} \Omega$ for the theoretical value of $f_{o}=165.8 \mathrm{kHz}$, and only $g_{m 2}$ changed, with different values of 1, 1.5, 2 and $3 \mathrm{mS}$. This resulted in an NBPF at a voltage output of $\mathrm{V}_{\mathrm{BP} 5}$ with voltage gains of $0,3.52,6.02$ and $9.54 \mathrm{~dB}$. Figure 29 shows the measurement results of the $V_{\mathrm{BP} 5}$ gain response. The component values used in Figure 28 were $\mathrm{C}_{3}=\mathrm{C}_{4}=$ $0.96 \mathrm{nF}, \mathrm{g}_{\mathrm{m} 1}=\mathrm{g}_{\mathrm{m} 2}=\mathrm{g}_{\mathrm{m} 3}=1 \mathrm{mS}$ and $\mathrm{R}_{4}=\mathrm{R}_{6}=1 \mathrm{k} \Omega$ for a theoretical value of $\mathrm{f}_{\mathrm{o}}=165.8 \mathrm{kHz}$, and only $R_{5}$ changed, with different values of $1,4,11$ and $19 \mathrm{k} \Omega$. This resulted in an NBPF at a voltage output of $\mathrm{V}_{\mathrm{BP} 6}$ with voltage gains of 6.12, 13.9, 21.3 and $25.52 \mathrm{~dB}$. Figure 30 shows the measurement results of the $\mathrm{V}_{\mathrm{BP} 6}$ gain response. To display the independent electronically adjusted passband gains from Figure $3 \mathrm{a}$, the value of $\mathrm{g}_{\mathrm{m} 2}$ was changed from $1 \mathrm{mS}$ to $4 \mathrm{mS}$, and the NBPF voltage gain at the voltage output of $\mathrm{V}_{\mathrm{BP} 5}$ could be changed from $0 \mathrm{~dB}$ to $12.04 \mathrm{~dB}$. As is shown in Figure 31, the proposed NBPF from Figure 3a exhibited independent electronic adjustment of the passband gains at a voltage output of $V_{\mathrm{BP} 5}$. To display the maximum operating passband gains from Figure $3 a$, the value of $R_{5}$ was changed from $1 \mathrm{k} \Omega$ to $25 \mathrm{k} \Omega$, and the NBPF voltage gain at the voltage output of $V_{\mathrm{BP} 6}$ could be changed from $6.02 \mathrm{~dB}$ to $28.3 \mathrm{~dB}$. As is shown in Figure 32, the proposed NBPF from Figure $3 a$ exhibited a wide range of independent amplitude adjustable passbands at the voltage output of $\mathrm{V}_{\mathrm{BP} 6}$. Figure 33 shows the theoretical, simulated and measured NBPF responses on the $V_{\text {BP5 }}$ output terminal with different values of $R_{4}$ when $C_{3}=C_{4}=$ $0.96 \mathrm{nF}, \mathrm{R}_{5}=\mathrm{R}_{6}=1 \mathrm{k} \Omega$ and $\mathrm{g}_{\mathrm{m} 1}=\mathrm{g}_{\mathrm{m} 2}=\mathrm{g}_{\mathrm{m} 3}=1 \mathrm{mS}$. Figure 34 shows the measurement results of the $V_{B P 5}$ gain response with different $Q$ values. In this case, the four values of $R_{4}$ were changed to $1,1.5,2$ and $3 \mathrm{k} \Omega$, and the measured values of $Q$ were 1.14, 1.59, 2.06 and 2.98 , respectively. As is shown in Figures 33 and 34, the Q parameter of the NBPF could be independently controlled by adjusting the different values of $R_{4}$ without affecting the parameters of $f_{0}$, as depicted in Equations (28) and (29). For the experimental test, Figure 35 shows the input and output voltage waveforms of the NBPF response at the $V_{\mathrm{BP} 5}$ output terminal, which could be extended to an amplitude of $120 \mathrm{mVpp}$ without signification distortion. As shown in Figure 35, the input voltage waveform was a 165.8-kHz sinusoidal waveform, and the output voltage waveform was measured as a $165.8-\mathrm{kHz}$ sinusoidal waveform with a phase difference of $0.57^{\circ}$. Figure 36 shows the frequency spectrum of the NBPF response at the $\mathrm{V}_{\mathrm{BP} 5}$ output terminal. The NBPF response center frequency measured at the output of $\mathrm{V}_{\mathrm{BP} 5}$ was $165.8 \mathrm{kHz}$. The THD, including the fundamental harmonic through the sixth harmonic components of Figure 36, was about $1.12 \%$. Figure 37 shows the THD result of the NBPF response at the $V_{\text {BP5 }}$ output terminal with different input voltages while keeping a constant center frequency of $165.8 \mathrm{kHz}$. Figure 38 shows the spectrum of the NBPF at the output of $\mathrm{V}_{\mathrm{BP} 5}$, which was obtained by applying two-tone signals $\mathrm{f}_{1}$ and $f_{2}$ around the theoretical value of $f_{o}=165.8 \mathrm{kHz}$ for IMD characterization. In Figure 38, the low-frequency tones of $\mathrm{f}_{1}=164.8 \mathrm{kHz}$ and the high-frequency tones of $\mathrm{f}_{2}=166.8 \mathrm{kHz}$ were used with input amplitudes of $63 \mathrm{mVpp}$. The measured value of the IMD3 was about $-39.66 \mathrm{dBc}$, and the TOI was about $-5.753 \mathrm{dBm}$. Figure 39 shows the P1dB of the NBPF measured at the output of $\mathrm{V}_{\mathrm{BP} 5}$ between the output power and the input power when the center frequency was $165.8 \mathrm{kHz}$. The measured output power P1dB was about $-9.77 \mathrm{dBm}$. Figure 40 shows the phase noise performance of the NBPF measured at the output of $V_{\text {BP5 }}$. The measured value of the phase noise of $\mathrm{V}_{\mathrm{BP} 5}$ was less than $-73.87 \mathrm{dBc} / \mathrm{Hz}$ at a $30-\mathrm{Hz}$ offset. According to the NBPF frequency spectrum measured in Figure 36, the dynamic range between the fundamental tone and the largest spurious of the spurious-free dynamic 
range was approximately $40.86 \mathrm{~dB}$. Thus, the FoM of the proposed VM NBPF at the voltage output of $\mathrm{V}_{\mathrm{BP} 5}$ was approximately computed to be $3.08 \times 10^{6}$.

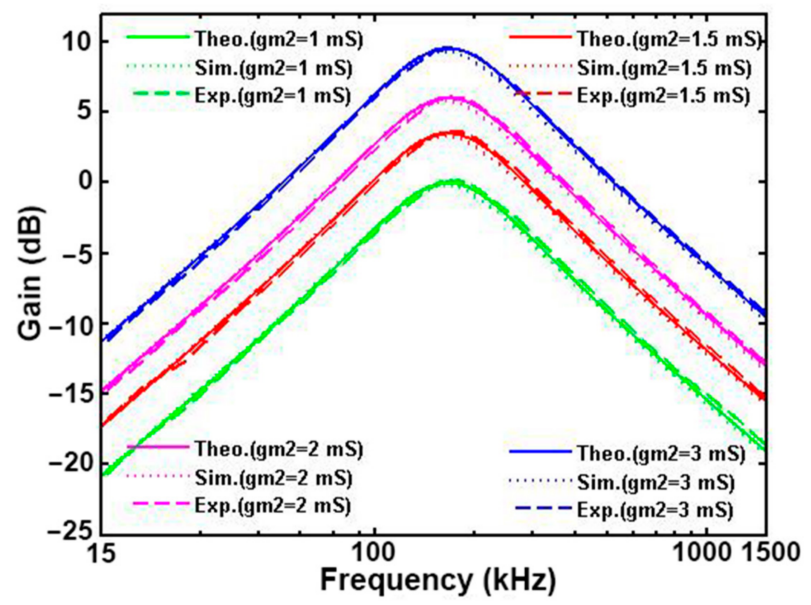

Figure 27. The theoretical, simulated and measured NBPF responses at the voltage output of $\mathrm{V}_{\mathrm{BP} 5}$ when $g_{\mathrm{m} 2}$ was varied.

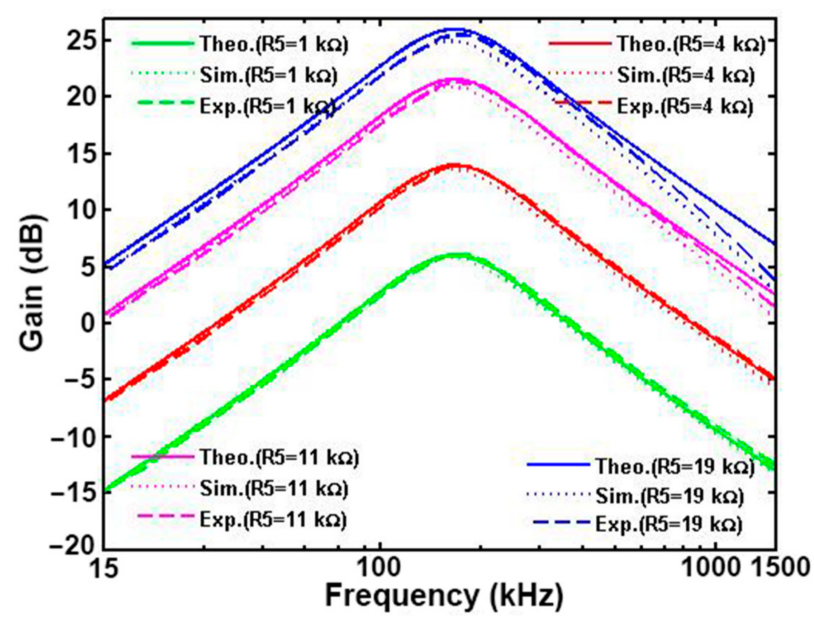

Figure 28. The theoretical, simulated and measured NBPF responses at the voltage output of $\mathrm{V}_{\mathrm{BP} 6}$ when $R_{5}$ was varied.

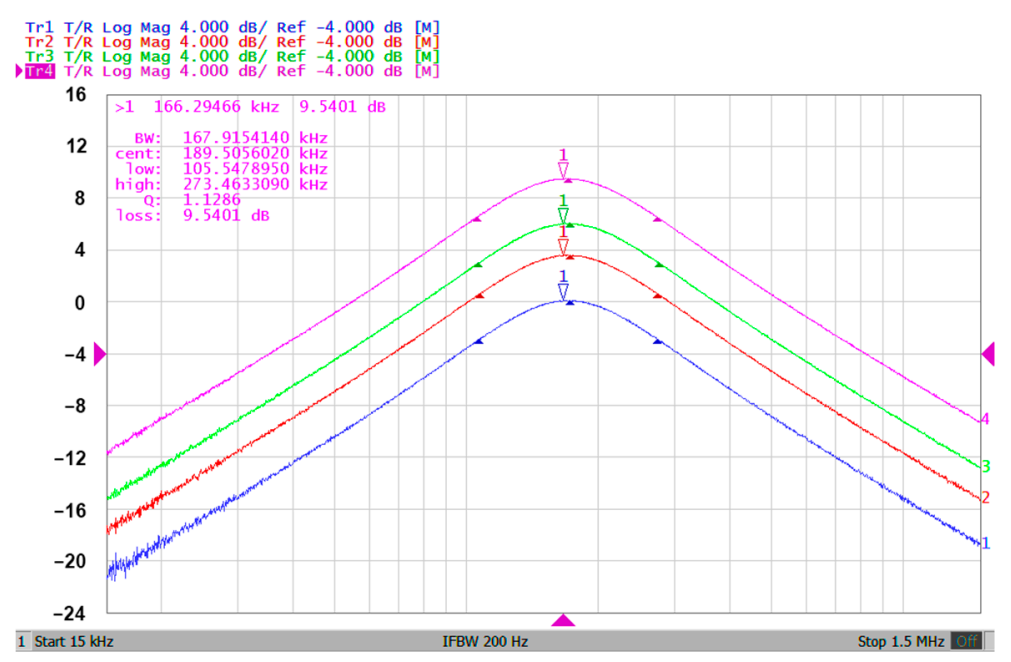

Figure 29. The measured magnitude responses of the $V_{\mathrm{BP} 5}$ when $g_{\mathrm{m} 2}$ was varied. 


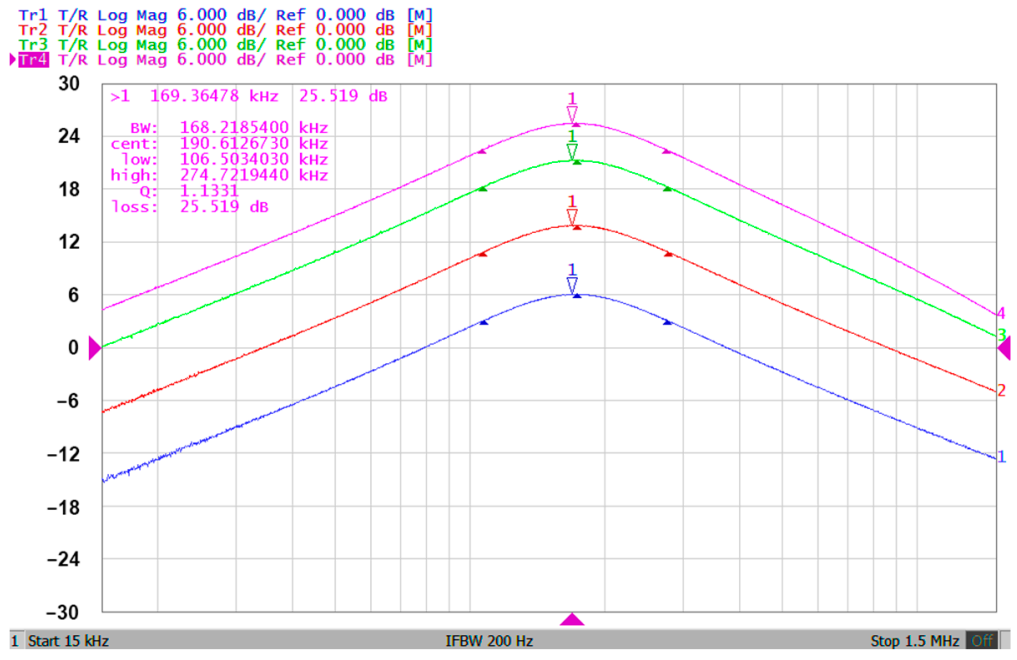

Figure 30. The measured magnitude responses of the $V_{\mathrm{BP} 6}$ when $\mathrm{R}_{5}$ was varied.

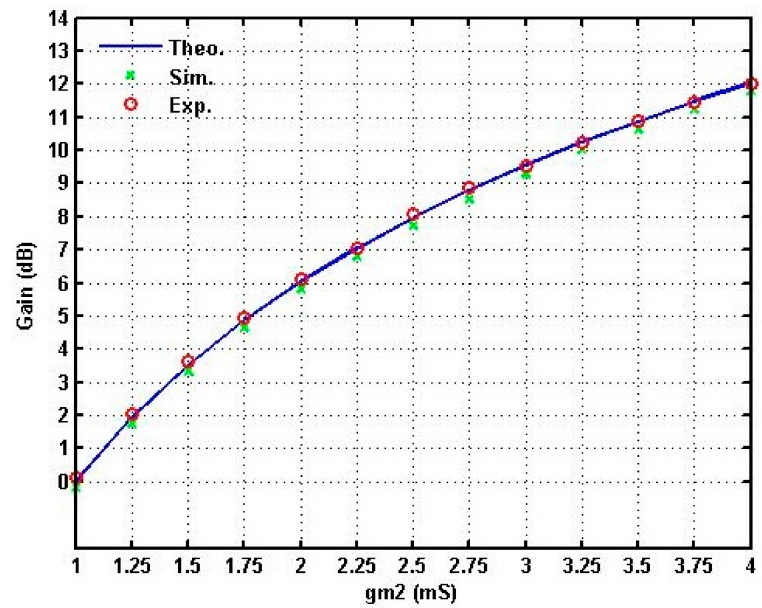

Figure 31. The theoretical, simulated and measured results of the electronic amplitude adjustable $\mathrm{NBPF}$ voltage gains at a voltage output of $\mathrm{V}_{\mathrm{BP} 5}$.

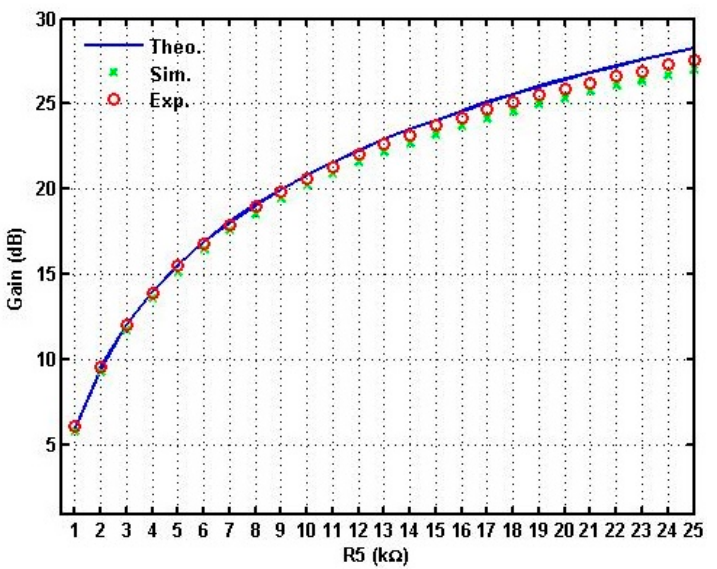

Figure 32. The theoretical, simulated and measured results of the independent amplitude adjustable $\mathrm{NBPF}$ voltage gains at a voltage output of $\mathrm{V}_{\mathrm{BP}}$. 


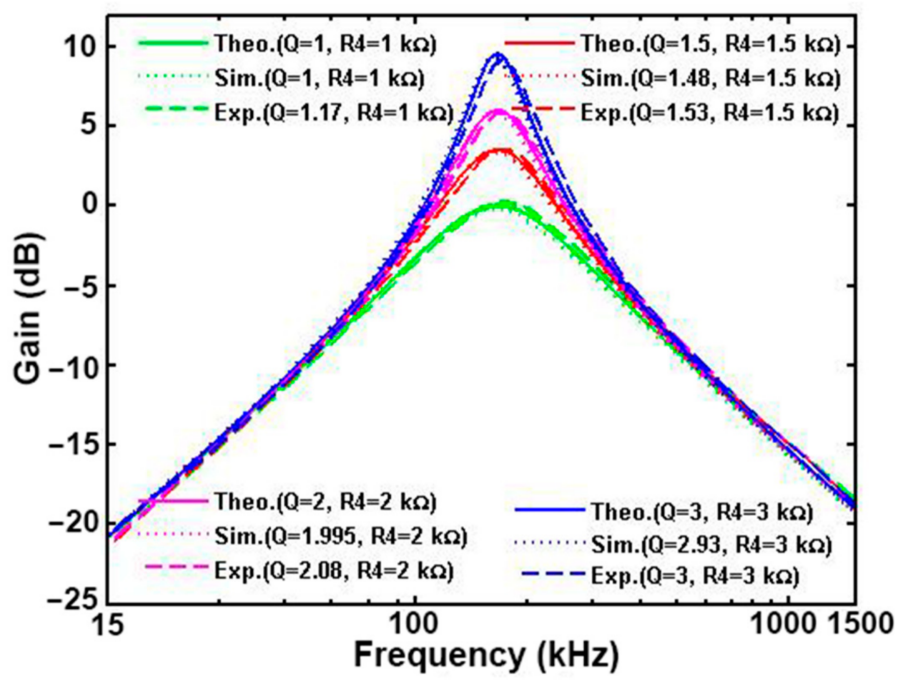

Figure 33. The $Q$ parameters of $N B P F$ at the output of $V_{B P 5}$ by varying $R_{4}$ while keeping $f_{0}$.

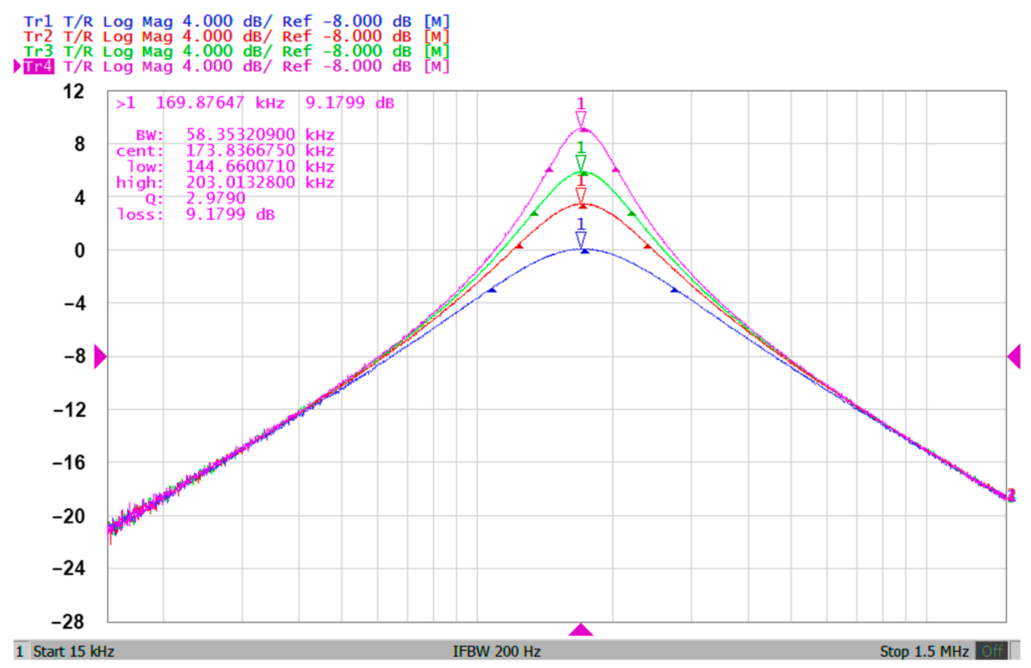

Figure 34. The measured magnitude responses of the $V_{B P 5}$ with different $Q$ values by varying $R_{4}$ while keeping $\mathrm{f}_{\mathrm{o}}$.

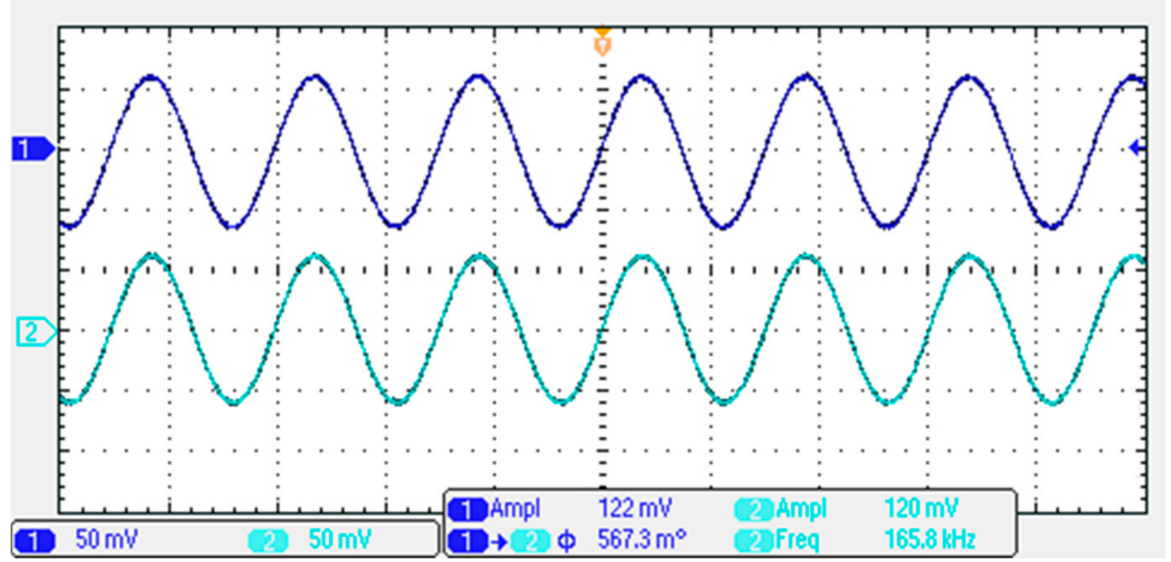

Figure 35. The measured time domain input and output voltage waveforms of the NBPF at the output of $\mathrm{V}_{\mathrm{BP} 5}$. 


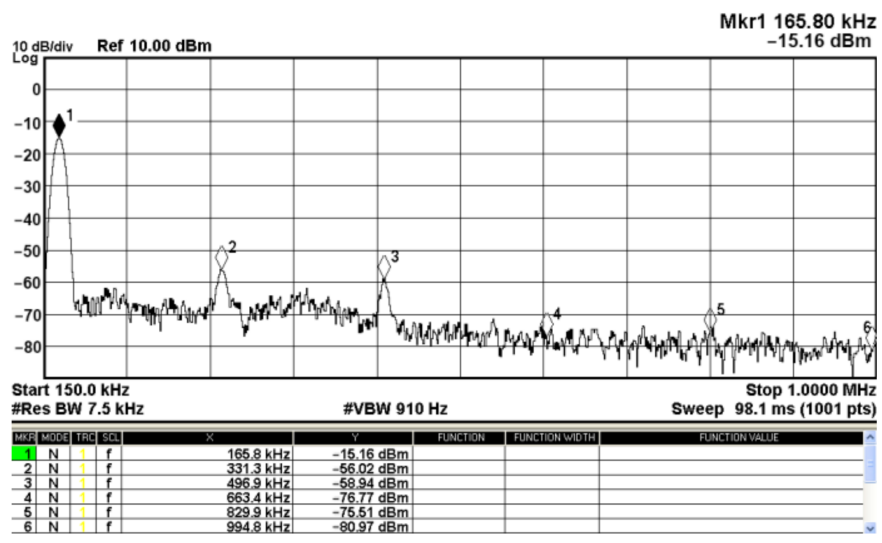

Figure 36. The frequency spectrum results of the NBPF at the output of $V_{B P 5}$.

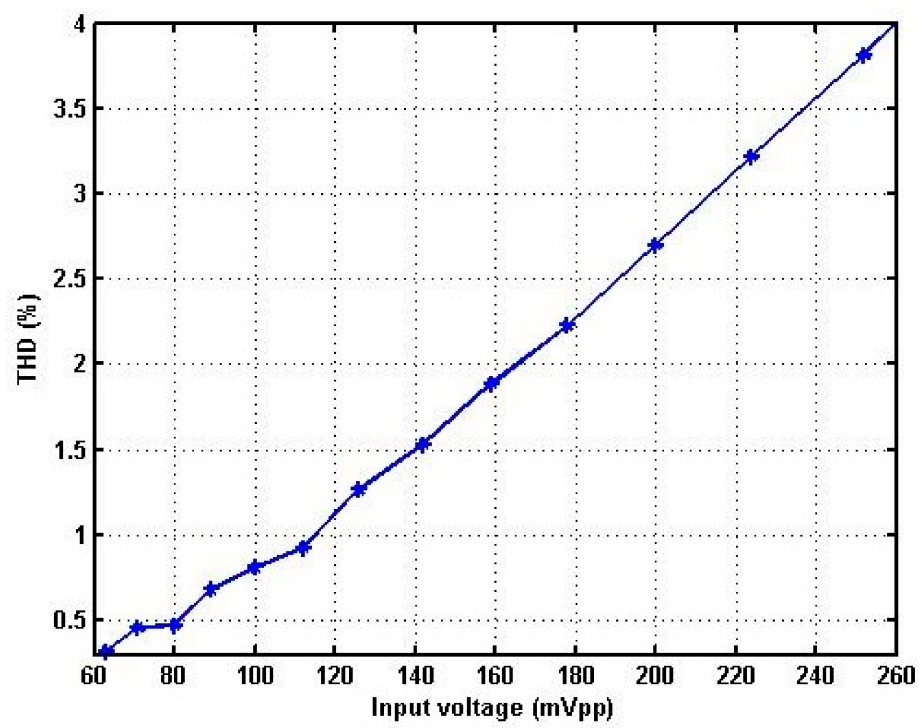

Figure 37. THD analysis results of the NBPF at the output of $\mathrm{V}_{\mathrm{BP} 5}$ with different input voltages.

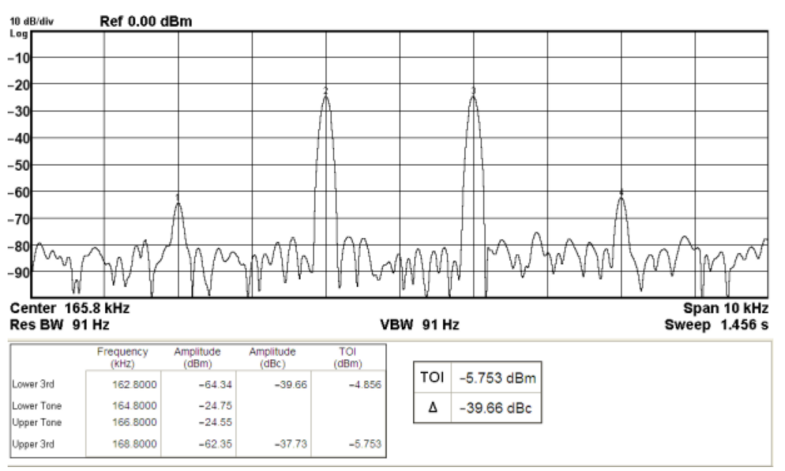

Figure 38. The NBPF at the $\mathrm{V}_{\mathrm{BP} 5}$ output spectrum for a two-tone intermodulation distortion test. 


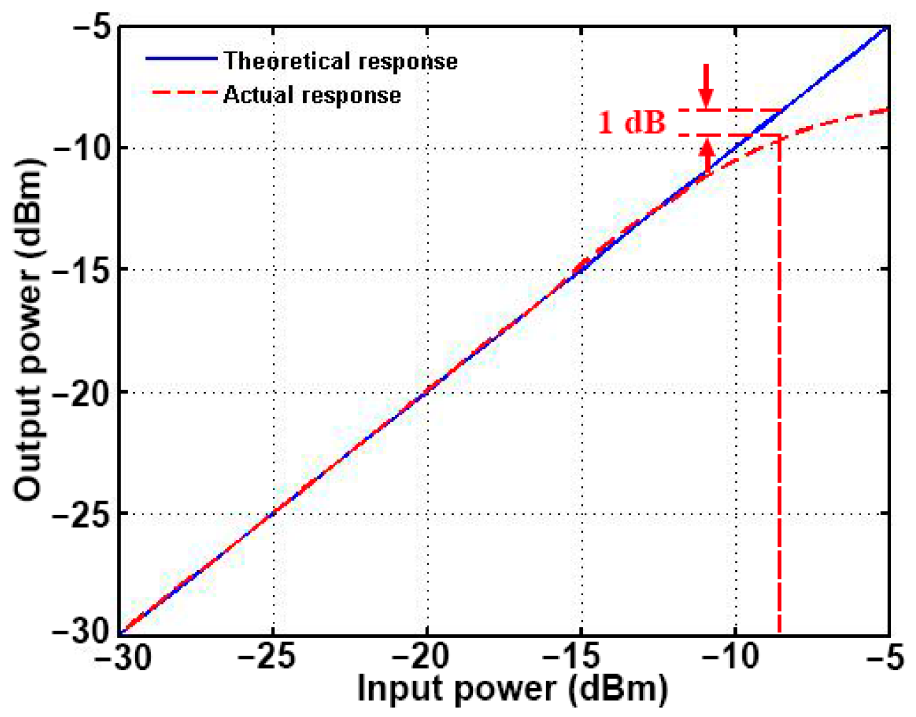

Figure 39. The measured P1dB of the NBPF at $V_{B P 5}$ with the input power when $f_{O}$ was $165.8 \mathrm{kHz}$.

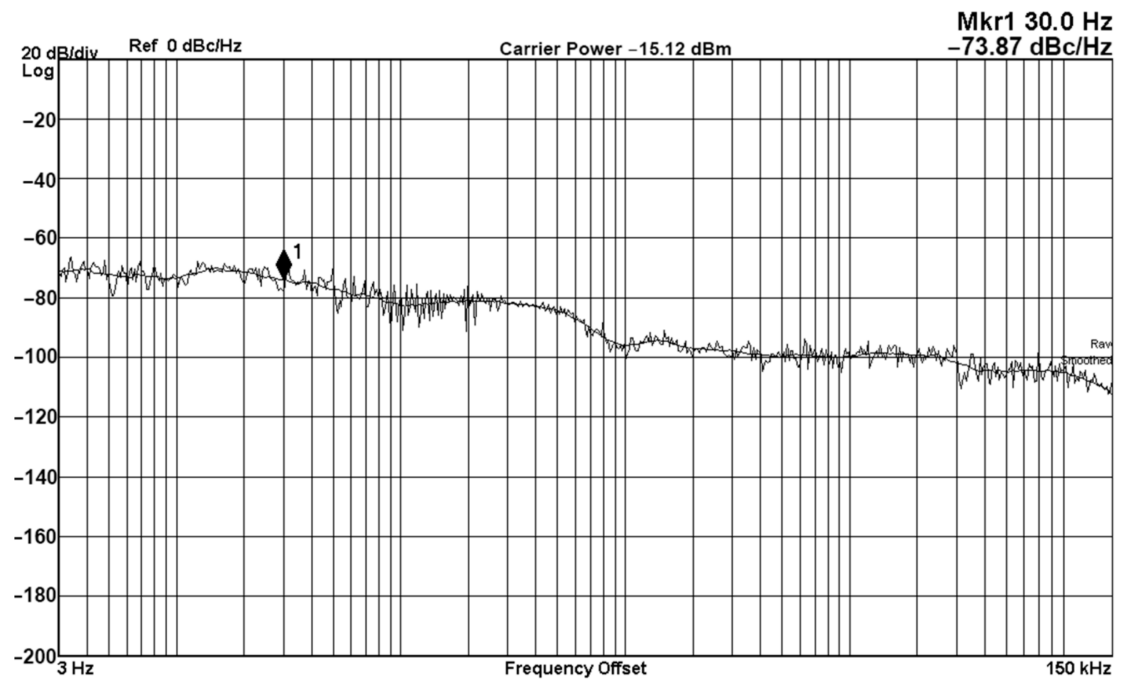

Figure 40. The measured phase noise performance of the NBPF at $\mathrm{V}_{\mathrm{BP} 5}$.

To investigate the VM fully uncoupled QSO in Figure 3b, Figure 41 shows the measured waveforms of the quadrature voltage outputs $\mathrm{V}_{\mathrm{O} 4}$ and $\mathrm{V}_{\mathrm{O} 5}$ in the time domain. The component values used in Figure 41 were $C_{3}=C_{4}=0.96 \mathrm{nF}, g_{\mathrm{m} 1}=g_{\mathrm{m} 2}=g_{\mathrm{m} 3}=1 \mathrm{mS}$ and $\mathrm{R}_{4}$ $=R_{5}=R_{6}=1 \mathrm{k} \Omega$ for the theoretical value of $f_{o}=165.8 \mathrm{kHz}$. The measured FO in Figure 41 was $161.3 \mathrm{kHz}$, which was close to the theoretical value of $165.8 \mathrm{kHz}$. Figure 42 shows the spectrum of the VM fully uncoupled QSO at the $\mathrm{V}_{\mathrm{o} 5}$ output terminal. The measured FO was $164 \mathrm{kHz}$, which was close to the theoretical value of $165.8 \mathrm{kHz}$. The difference between the amplitudes of the fundamental and second harmonics was $49.67 \mathrm{~dB}$, and the calculated THD was about $0.33 \%$. As is shown in Figure 42, the third harmonic and subsequent harmonics were not visible in the spectrum, because these harmonics were lower than the noise floor. This means that the THD of the second proposed VM fully uncoupled QSO was small. Figure 43 shows the phase noise performance of the QSO measured at the output of $\mathrm{V}_{\mathrm{o} 5}$. The measured value of the phase noise of $\mathrm{V}_{\mathrm{o}}$ was less than $-34.7 \mathrm{dBc} / \mathrm{Hz}$ at a $30-\mathrm{Hz}$ offset. Figure 44 shows the $\mathrm{FO}$ tuning range of the measured output voltage $\mathrm{V}_{\mathrm{o}}$, where $\mathrm{C}_{3}$ $=\mathrm{C}_{4}=0.96 \mathrm{nF}, \mathrm{g}_{\mathrm{m} 2}=1 \mathrm{mS}$ and $\mathrm{R}_{4}=\mathrm{R}_{5}=\mathrm{R}_{6}=1 \mathrm{k} \Omega$, and only $\mathrm{g}_{\mathrm{m} 1}=\mathrm{g}_{\mathrm{m} 3}$ were varied at values from $0.5 \mathrm{mS}$ to $10 \mathrm{mS}$. As is shown in Figure 44, the measured oscillation frequency was electronically and linearly varied from $80.83 \mathrm{kHz}$ to $1626 \mathrm{kHz}$. In Figures 41-44, the 
$\mathrm{g}_{\mathrm{m} 2}$ value should have been slightly adjusted to satisfy the $\mathrm{CO}$, as depicted in Equation (34). Figure 45 shows the relationship between the measured amplitude ratio of the quadrature output voltages $V_{04}$ and $V_{05}$ and the $F O$ as depicted in Equation (38). Figure 46 shows the relationship between the measured phase difference of the quadrature output voltages $\mathrm{V}_{\mathrm{o} 4}$ and $\mathrm{V}_{\mathrm{o} 5}$ and the $\mathrm{FO}$ as depicted in Equation (39). Figure 47 shows the experimental results of the voltage gain of $V_{06}$ when only $R_{5}$ was changed while maintaining $C_{3}=C_{4}=$ $0.96 \mathrm{nF}, \mathrm{g}_{\mathrm{m} 1}=\mathrm{g}_{\mathrm{m} 3}=1 \mathrm{mS}, \mathrm{g}_{\mathrm{m} 2}=1.05 \mathrm{mS}$ and $\mathrm{R}_{4}=\mathrm{R}_{6}=1 \mathrm{k} \Omega$. As is shown in Figure 47, the proposed VM fully uncoupled QSO (Figure $3 \mathrm{~b}$ ) exhibited a wide range of independent amplitude adjustable $\mathrm{V}_{\mathrm{o} 6}$ voltage gains. The measured operating amplitude control range could be adjusted from 1.51 to 24.03 . Table 5 summarizes the performance of the second proposed isomorphic circuit.

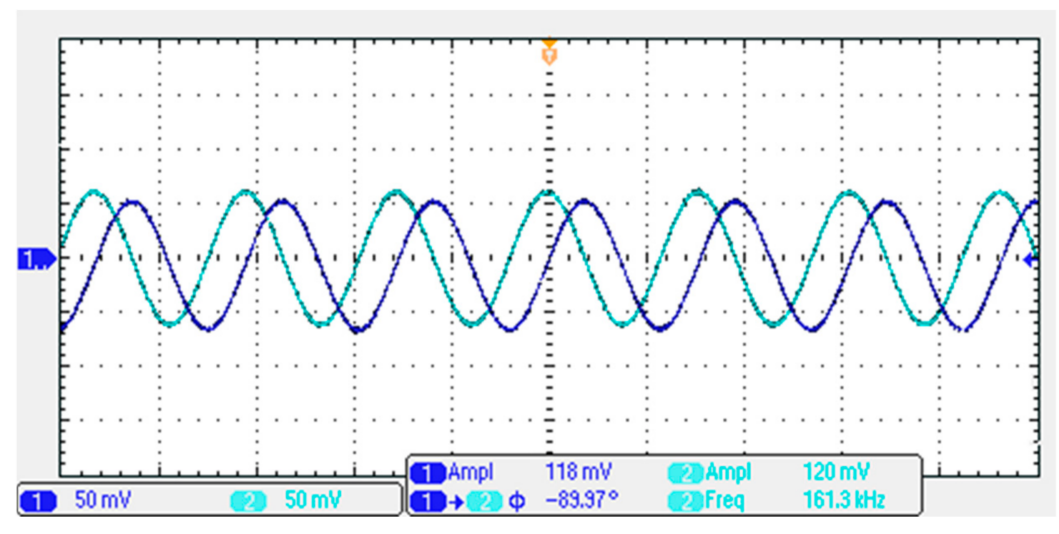

Figure 41. The measured waveforms of the quadrature voltage outputs $\mathrm{V}_{\mathrm{O} 4}$ and $\mathrm{V}_{\mathrm{o} 5}$ in the time domain.

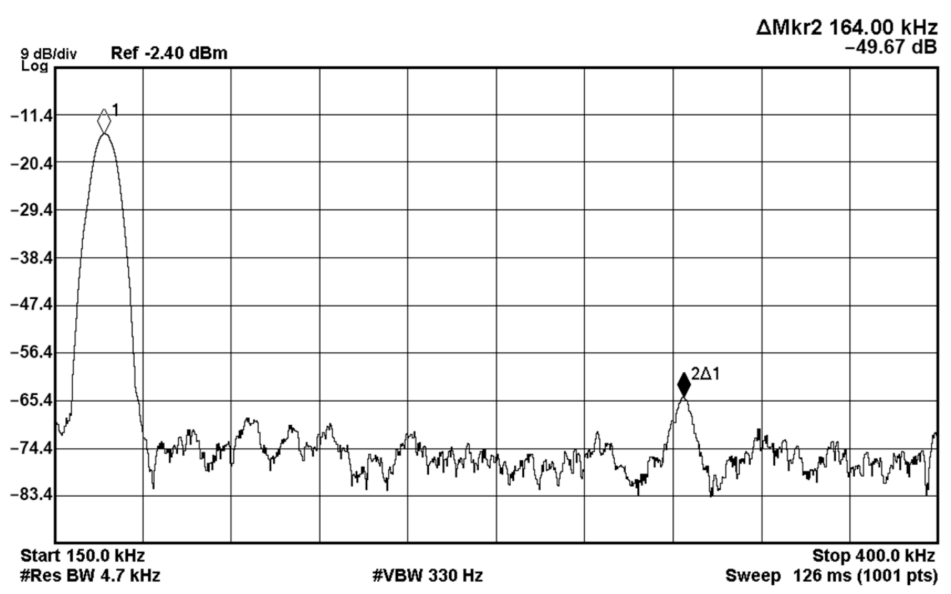

Figure 42. The frequency spectrum results of the VM fully uncoupled QSO at the $\mathrm{V}_{\mathrm{O} 5}$ output terminal. 


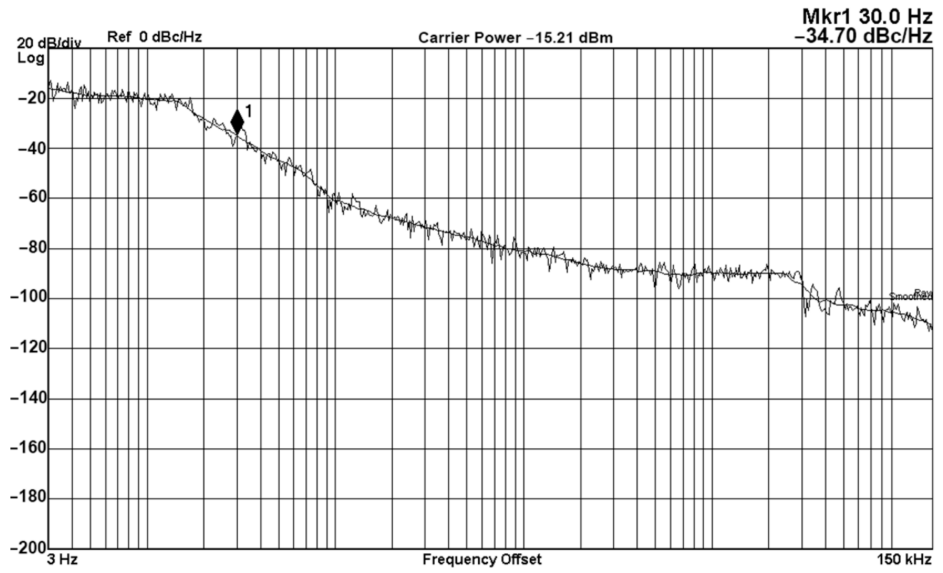

Figure 43. The measured phase noise performance of the VM QSO at the $\mathrm{V}_{\mathrm{o} 5}$ output terminal.

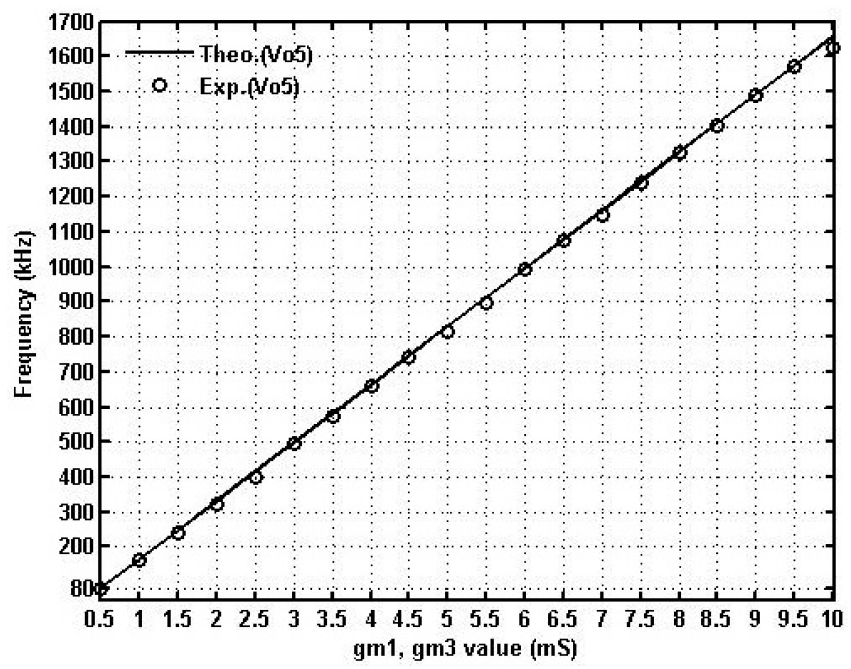

Figure 44. The experimental results of $\mathrm{V}_{\mathrm{o} 5}$ for $\mathrm{g}_{\mathrm{m} 1}=\mathrm{g}_{\mathrm{m} 3}$.

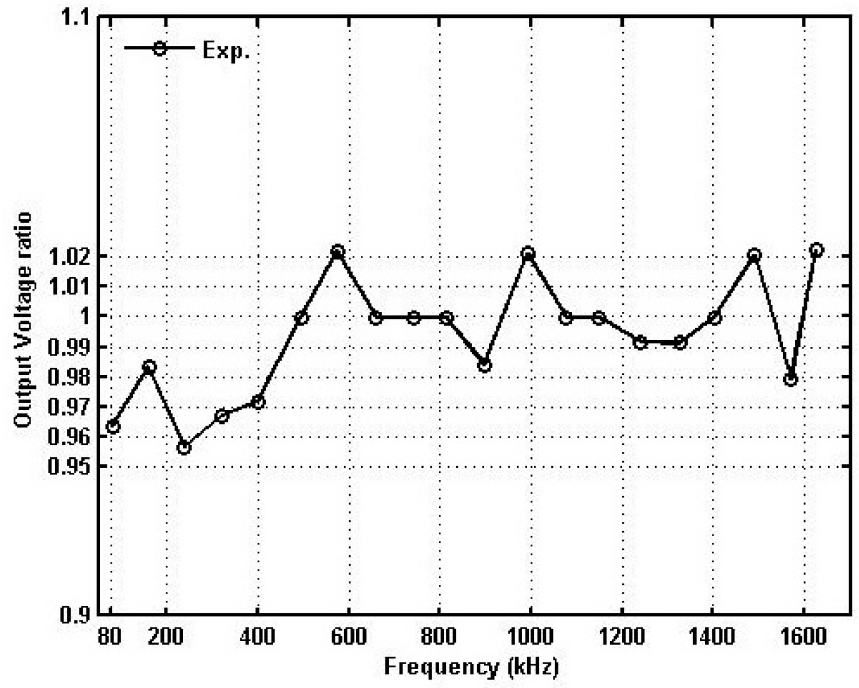

Figure 45. The measured amplitude ratio of quadrature output voltages $V_{04}$ and $V_{05}$ versus the tuning FO. 


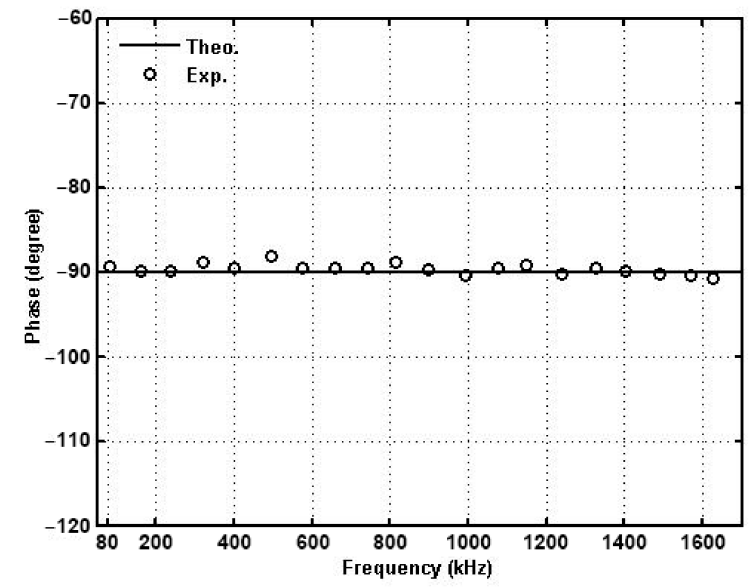

Figure 46. The measured phase difference of quadrature output voltages $V_{04}$ and $V_{05}$ versus the tuning FO.

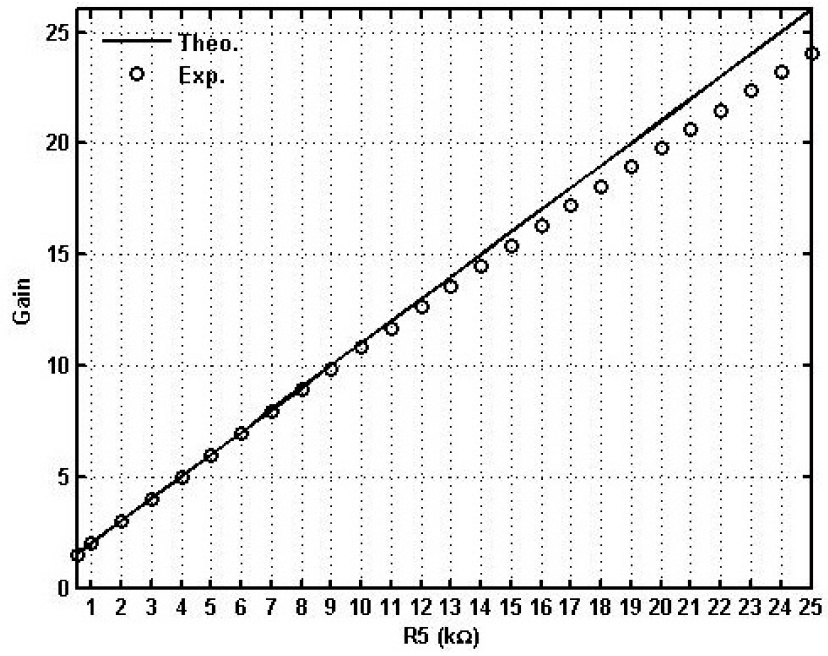

Figure 47. The experimental results of the $V_{06}$ voltage gain when $R_{5}$ was varied.

Table 5. Performance parameters of the performance of the second proposed isomorphic circuit.

\begin{tabular}{|c|c|}
\hline \multicolumn{2}{|l|}{ Non-Inverting Bandpass Filter Factor } \\
\hline Supply voltage $(\mathrm{V})$ & \pm 5 \\
\hline Power dissipation (W, measurement) & 0.22 \\
\hline Central frequency $(\mathrm{kHz}$, design/measurement) & $165.8 / 165.8$ \\
\hline Maximum operating voltage gain (dB, design/measurement) & $28.3 / 27.58$ \\
\hline Measured total harmonic distortion@ $\mathrm{V}_{\text {in }}=120 \mathrm{mV}_{\mathrm{PP}}(\%)$ & 1.12 \\
\hline Measured output 1-dB compression point $(\mathrm{dBm})$ & -9.77 \\
\hline Measured third-order intermodulation distortion at $63 \mathrm{mV}_{\mathrm{PP}}(\mathrm{dBc})$ & -39.66 \\
\hline Measured third-order intercept point $(\mathrm{dBm})$ & -5.753 \\
\hline Measured phase noise at $30 \mathrm{~Hz}(\mathrm{dBc} / \mathrm{Hz})$ & -73.87 \\
\hline Measured spurious-free dynamic range $(\mathrm{dB})$ & 40.86 \\
\hline Figure of merit & $3.08 \times 10^{6}$ \\
\hline \multicolumn{2}{|l|}{ Fully Uncoupled Quadrature Oscillator Factor } \\
\hline Supply voltage $(\mathrm{V})$ & \pm 5 \\
\hline Power dissipation (W, measurement) & 0.22 \\
\hline Number of sinusoidal voltage output used & 3 \\
\hline Oscillation frequency (kHz, design/measurement) & $165.8 / 161.3$ \\
\hline Measured total harmonic distortion (\%) & 0.33 \\
\hline Measured phase noise at $30 \mathrm{~Hz}(\mathrm{dBc} / \mathrm{Hz})$ & -34.7 \\
\hline Measured operating oscillation frequency range $(\mathrm{kHz})$ & $80.83 \sim 1626$ \\
\hline Measured operating amplitude control range & $1.51 \sim 24.03$ \\
\hline
\end{tabular}




\section{Concluding Remarks}

This paper proposes isomorphic circuits with independent amplitude control function VM NBPFs and VM fully uncoupled QSOs. The proposed VM NBPFs and VM fully uncoupled QSOs employ three LT1228 commercial ICs, two grounded capacitors and three resistors. The proposed isomorphic circuits exhibit low-output impedance and independent amplitude control, which are important for easily cascading the VM operation and independent control of the amplitude gain. The $Q$ and $f_{o}$ parameters of all the proposed NBPF responses are orthogonally adjustable. The passband gain of all the proposed NBPFs can be adjusted independently without affecting $Q$ and $f_{0}$. The measured passband gains of the first proposed NBPF response can be independently tuned to $27.86 \mathrm{~dB}$, and the measured phase noise is less than $-83.86 \mathrm{dBc} / \mathrm{Hz}$ at a $30-\mathrm{Hz}$ offset. The measured spurious-free dynamic range of the first proposed NBPF response was approximately $40.79 \mathrm{~dB}$, and the calculated FoM was $3.07 \times 10^{6}$. The measured passband gains of the second proposed NBPF response can be independently tuned to $27.58 \mathrm{~dB}$, and the measured phase noise is less than $-73.87 \mathrm{dBc} / \mathrm{Hz}$ at a $30-\mathrm{Hz}$ offset. The measured spurious-free dynamic range of the second proposed NBPF response was approximately $40.86 \mathrm{~dB}$, and the calculated FoM was $3.08 \times 10^{6}$. By feeding back each input signal to the NBPF response, the VM fully uncoupled QSO could be obtained. During FO tuning, the voltage amplitude ratio of the quadrature output was equal. The FO could be electronically and linearly controlled by the bias current of the LT1228 IC, and one sinusoidal waveform could be independently controlled without any additional active devices. The experimental measurements confirmed the workability of the isomorphic circuits. Since the proposed isomorphic circuits have independent amplitude control functions for the NBPFs and QSOs, these isomorphic circuits are expected to have a wide variety of applications in the future, such as in phase-sensitive detection, signal processing, instrumentation, telecommunication and power systems.

Author Contributions: S.-F.W. and H.-P.C. conceived and designed the theoretical verifications; Y.K. revised the manuscript to improve the quality of English; H.-P.C. analyzed the results and wrote the paper; W.-Y.C. performed the simulations and experiments. All authors have read and agreed to the published version of the manuscript.

Funding: This research received no external funding.

Institutional Review Board Statement: Not applicable.

Informed Consent Statement: Not applicable.

Data Availability Statement: Not applicable.

Conflicts of Interest: The authors declare no conflict of interest.

\section{References}

1. Olsak, M.; Vrba, K.; Matejicek, L. Electronically tunable high-order highpass filters with minimum of components. J. Electr. Eng. 2003, 54, 57-62.

2. Siripongdee, S.; Jaikla, W. Electronically controllable grounded inductance simulators using single commercially available IC: LT1228. AEU-Int. J. Electron. Commun. 2017, 76, 1-10. [CrossRef]

3. Siripongdee, S.; Jaikla, W. Universal filter using single commercially available IC: LT1228. In Proceedings of the 2016 the 3rd International Conference on Mechatronics and Mechanical Engineering, Kuala Lumpur, Malaysia, 28-30 November 2017; Volume 95, p. 14022.

4. Rungsa, S.; Jantakun, A. Single commercially available IC: LT1228 based sinusoidal oscillator. Prz. Elektrotechniczny 2019, 95, 218-222. [CrossRef]

5. Klungtong, S.; Thanapatay, D.; Jaikla, W. Three-input single-output voltage-mode multifunction filter with electronic controllability based on single commercially available IC. Act. Passiv. Electron. Compon. 2017, 2017, 5240751. [CrossRef]

6. Chaichana, A.; Siripongdee, S.; Jaikla, W. Electronically adjustable voltage-mode first-order allpass filter using single commercially available IC. In Proceedings of the 2019 International Conference on Smart Materials Applications, Tokyo, Japan, 19-22 January 2019; p. 012009.

7. Wai, M.P.P.; Chaichana, A.; Jaikla, W.; Siripongdee, S.; Suwanjan, P. One input voltage and three output voltage universal biquad filters with orthogonal tune of frequency and bandwidth. Int. J. Electr. Comput. Eng. 2021, 20, 2962-2973. 
8. Roongmuanpha, N.; Suesut, T.; Tangsrirat, W. Electronically tunable triple-input single-output voltage-mode biquadratic filter implemented with single integrated circuit package. Adv. Sci. Technol. Eng. Syst. J. 2021, 6, 1120-1127. [CrossRef]

9. Wang, H.Y.; Tran, H.D.; Nguyen, Q.M.; Yin, L.T.; Liu, C.Y. Derivation of oscillators from biquadratic band pass filters using circuit transformations. Appl. Sci. 2014, 4, 482-492. [CrossRef]

10. Tran, H.D.; Wang, H.Y.; Lin, M.C.; Nguyen, Q.M. Synthesis of cascadable DDCC-based universal filter using NAM. Appl. Sci. 2015, 5, 320-343. [CrossRef]

11. Minaei, S.; Sayin, O.K.; Kuntman, H. A new CMOS electronically tunable current conveyor and its application to current-mode filters. IEEE Trans. Circuits Syst. I 2006, 53, 1448-1457. [CrossRef]

12. Herencsar, N.; Koton, J.; Hanak, P. Universal voltage conveyor and its novel dual-output fully-cascadable VM APF application. Appl. Sci. 2017, 7, 307. [CrossRef]

13. Sotner, R.; Jerabek, J.; Langhammer, L.; Dvorak, J. Design and analysis of CCII-based oscillator with amplitude stabilization employing optocouplers for linear voltage control of the output frequency. Electronics 2018, 7, 157. [CrossRef]

14. Ullah, F.; Liu, Y.; Li, Z.; Wang, X.; Sarfraz, M.M.; Zhang, H. A bandwidth-enhanced differential LC-voltage controlled oscillator (LC-VCO) and superharmonic coupled quadrature VCO for K-band applications. Electronics 2018, 7, 127. [CrossRef]

15. Safari, L.; Barile, G.; Ferri, G.; Stornelli, V. A new low-voltage low-power dual-mode VCII-based SIMO universal filter. Electronics 2019, 8, 765. [CrossRef]

16. Márquez, A.; Pérez-Bailón, J.; Calvo, B.; Medrano, N.; Martínez, P.A. A CMOS self-contained quadrature signal generator for SoC impedance spectroscopy. Sensors 2018, 18, 1382. [CrossRef]

17. Acosta, L.; Jimenez, M.; Carvajal, R.G.; Lopez-Martin, A.J.; Ramirez-Angulo, J. Highly linear tunable CMOS gm-C low-pass filter. IEEE Trans. Circuits Syst. I Regul. Pap. 2009, 56, 2145-2158. [CrossRef]

18. Kumngern, M.; Aupithak, N.; Khateb, F.; Kulej, T. 0.5 V fifth-order butterworth low-pass filter using multiple-input OTA for ECG applications. Sensors 2020, 20, 7343. [CrossRef]

19. Jaikla, W.; Khateb, F.; Kulej, T.; Pitaksuttayaprot, K. Universal filter based on compact CMOS structure of VDDDA. Sensors 2021, 21, 1683. [CrossRef]

20. Psychalinos, C.; Kasimis, C.; Khateb, F. Multiple-input single-output universal biquad filter using single output operational transconductance amplifiers. AEU-Int. J. Electron. Commun. 2018, 93, 360-367. [CrossRef]

21. Wang, S.F.; Chen, H.P.; Ku, Y.; Lin, Y.C. Versatile tunable voltage-mode biquadratic filter and its application in quadrature oscillator. Sensors 2019, 19, 2349. [CrossRef] [PubMed]

22. Wang, S.F.; Chen, H.P.; Ku, Y.; Yang, C.M. Independently tunable voltage-mode OTA-C biquadratic filter with five inputs and three outputs and its fully-uncoupled quadrature sinusoidal oscillator application. AEU-Int. J. Electron. Commun. 2019, 100, 152822. [CrossRef]

23. Jaikla, W.; Adhan, S.; Suwanjan, P.; Kumngern, M. Current/voltage controlled quadrature sinusoidal oscillators for phase sensitive detection using commercially available IC. Sensors 2020, 20, 1319. [CrossRef] [PubMed]

24. Wang, S.F.; Chen, H.P.; Ku, Y.; Lee, C.L. Versatile voltage-mode biquadratic filter and quadrature oscillator using four OTAs and two grounded capacitors. Electronics 2020, 9, 1493. [CrossRef]

25. LT1228-100 MHz Current Feedback Amplifier with DC Gain Control. Linear Technology Corporation Version Number D. 2012. Available online: http:/ / www.linear.com/product/LT1228 (accessed on 1 October 2019).

26. Koton, J.; Vrba, K.; Herencsar, N. Voltage-mode full-wave rectifier based on DXCCII. Analog Integr. Circuits Signal. Process. 2014, 81, 99-107. [CrossRef]

27. Martin, R.S.; Tello, P.; Valencia, A.; Marzo, A. Experimental evaluation of distortion in amplitude modulation techniques for parametric loudspeakers. Appl. Sci. 2020, 10, 2070. [CrossRef]

28. Alpaslan, H.; Yuce, E. DVCC+ based multifunction and universal filters with the high input impedance features. Analog Integr. Circuits Signal. Process. 2020, 103, 325-335. [CrossRef] 